\title{
41 Strategies for Optimizing Photosynthesis with Biotechnology to Improve Crop Yield
}

\author{
Wataru Yamori, Louis J. Irving, Shunsuke Adachi, and Florian A. Busch
}

\section{CONTENTS}

41.1 Introduction 741

41.2 Improving Photosynthetic Performance via Improvements in Rubisco Kinetics and N Allocation...........................741

41.2.1 Rubisco Specificity and Carboxylation Rate .................................................................................. 741

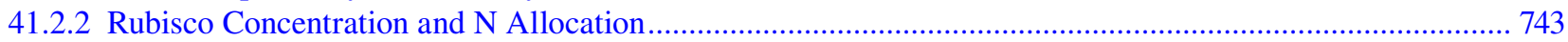

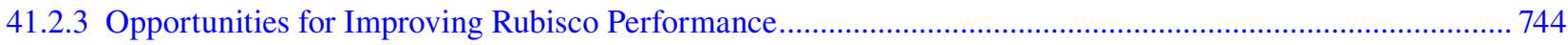

41.3 Increasing the Thermotolerance of Rubisco Activase to Maintain Higher Rubisco Activity under High Temperatures... 745

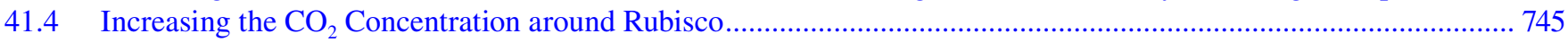

41.5 Enhancing the Rate of Chloroplast Electron Transport in the Thylakoid Membranes ............................................ 747

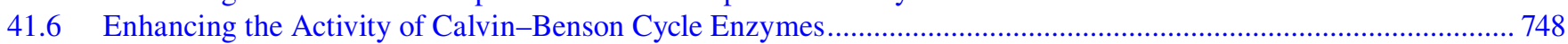

41.7 Enhancing the Capacity of Phloem Carbohydrate Transport and Carbon Utilization............................................... 750

41.8 Increasing Crop Yield by Optimizing Photosynthesis on the Canopy Level ....................................................... 750

41.9 Improving Photosynthetic Performance by QTL Analysis with Utilizing Natural Genetic Resources .................... 752

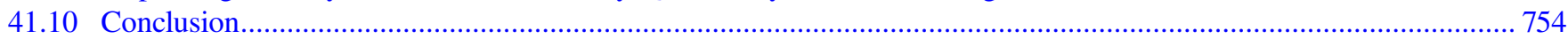

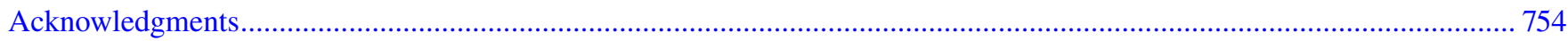

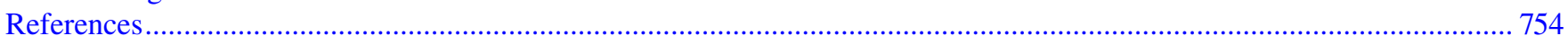

\subsection{INTRODUCTION}

The world's population is projected to increase to 9 billion by 2050 (Roberts 2011), while the availability of arable land will decrease as environmental degradation and destruction grow worse. Meeting the food demand of this growing population will be a major challenge, and a food shortage is projected. Therefore, it is imperative that we produce crops with improved quality and quantity using conventional selection and breeding, or genetic engineering, in order to meet the growing food demand through sustainable agricultural systems (Ashraf and Akram 2009).

In the past, large improvements in grain yield were achieved during the green revolution (Khush 2001); however, present rates of increase in crop yields are insufficient to keep pace with the rapid rates of global population growth. Thus, there is an urgent need to increase crop productivity beyond existing yield potentials to address the challenge of food security (Yamori 2013). Advances in biotechnology have led to increased opportunities to rapidly improve the crop production, for example, by facilitating the transfer of desired characteristics from other species, which is impossible through conventional plant breeding. Biotechnology for crop improvement has become a promising strategy to solve the food crisis.

So far, various crops have been engineered for enhanced resistance to various stresses such as herbicides, viruses, and abiotic stresses. The proportion of biomass partitioned into grain has already been brought close to its theoretical maximum thanks to plant breeding; thus, a fundamental limitation on plant productivity that has to be optimized for increasing crop yield is photosynthesis (Long et al. 2006). Photosynthesis is the process of converting light energy to chemical energy using $\mathrm{CO}_{2}$ and water, and of storing it as carbohydrates. Enhancing photosynthetic capacity of plants is a promising approach to increase crop productivity. This chapter summarizes the various approaches by genetic engineering applied to enhance photosynthetic capacity and plant production. The targets considered for possible candidates include Rubisco, Rubisco activase, enzymes of Calvin-Benson cycle, $\mathrm{CO}_{2}$ and carbohydrate transport, as well as photosynthetic electron transport (Figure 41.1). In addition, other areas that promise scope for photosynthetic improvement, such as altering canopy architecture or mining natural genetic variations for identifying new targets, are described.

\subsection{IMPROVING PHOTOSYNTHETIC PERFORMANCE VIA IMPROVEMENTS IN RUBISCO KINETICS AND N ALLOCATION}

\subsubsection{Rubisco Specificity and Carboxylation Rate}

Rubisco (ribulose-1,5-bisphosphate carboxylase/oxygenase; EC 4.1.1.39) is the enzyme responsible for the fixation of $\mathrm{CO}_{2}$ in 


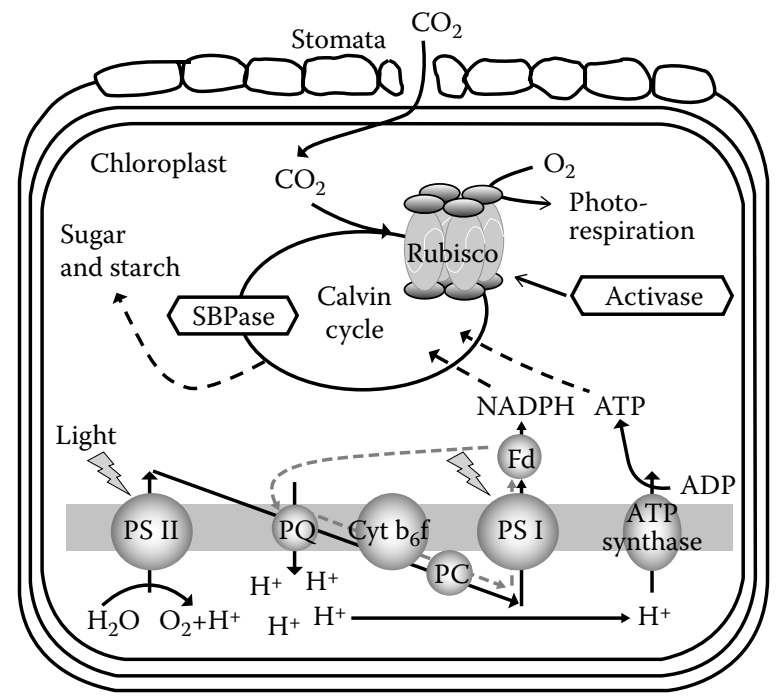

FIGURE 41.1 Scheme of $\mathrm{C}_{3}$ photosynthetic reactions. Light energy captured by chlorophyll drives electron transport, which is used to reduce $\mathrm{NADP}^{+}$to NADPH. Electron transport drives the translocation of $\mathrm{H}^{+}$from the stroma into the lumen, generating a $\mathrm{H}^{+}$electrochemical gradient and driving the production of ATP. ATP and NADPH produced by these reactions are now used to fix $\mathrm{CO}_{2}$ (photosynthesis) into carbohydrates and to react with $\mathrm{O}_{2}$ (photorespiration). Rubisco catalyzes the assimilation of $\mathrm{CO}_{2}$ in the carboxylation reaction of the Calvin-Benson cycle in the chloroplast. Reactions of the Calvin-Benson cycle utilize NADPH and ATP to produce triose phosphates, which are required for the synthesis of carbohydrates and then finally of sugar and/or starch. The NADPH and ATP are also used in a range of other metabolic activities (e.g., nitrogen and sulfur metabolism, lipid and pigment synthesis) in the chloroplast. Rubisco: ribulose-1,5-bisphosphate carboxylase/oxygenase, SBPase: sedoheptulose-1,7-bisphosphatase, PS II: photosystem II, PQ: plastoquinone, Cyt $b_{6}$ f: cytochrome $b_{6} / f$ complex, PC: plastocyanin, PS I: photosystem I, Fd: ferredoxin.

photosynthesis. It has a low catalytic efficiency, able to fix only around $2-4 \mathrm{CO}_{2}$ molecules per second in higher plants; thus, $20-30 \%$ of nitrogen in terrestrial $\mathrm{C}_{3}$ plant leaves is invested in Rubisco to maximally exploit the light environment (Galmés et al. 2014a). Given Rubisco's low catalytic efficiency, and the relatively high proportion of leaf nitrogen for which it accounts, numerous investigators have noted a strong positive correlation between leaf nitrogen content and photosynthetic rates (Evans 1989; Makino et al. 1997; Wright et al. 2004).

Rubisco can fix both carbon dioxide and oxygen in photosynthesis and photorespiration, respectively. Photosynthetic carbon fixation produces two molecules of phosphoglycerate (PGA) for every carbon fixed, while photorespiration produces one PGA and one phosphoglycolate (PGO). PGO must be recycled to PGA, with the loss of $\mathrm{CO}_{2}$ and ammonia. Although the released $\mathrm{CO}_{2}$ may be refixed by the chloroplasts, and the ammonia reassimilated in the leaves (Morris et al. 1988; Busch et al. 2013), photorespiration is generally considered to be a wasteful reaction.

To understand the reason Rubisco's oxygenase activity exists, we must consider the enzyme's evolutionary history.
Rubisco evolved around 3.5 Ga ago in an environment devoid of oxygen, and thus devoid of selection pressure against its oxygenase activity. The depletion of reduced iron and other chemicals in the oceans by photosynthetically evolved oxygen took around $1.3 \mathrm{Ga}$ and led to an increase in molecular oxygen both in the oceans and release of free $\mathrm{O}_{2}$ into the atmosphere (Schopf 2014), although by this time, despite the new selection pressure, Rubisco's oxygenase activity apparently could not be eliminated. Following the great oxygenation of $2.2 \mathrm{Ga}$, atmospheric $\mathrm{O}_{2}$ concentrations remained below $10 \%$ of current atmospheric levels until approximately $800 \mathrm{Ma}$ (Payne et al. 2009), while $\mathrm{CO}_{2}$ levels remained 10-20 times present levels until the evolution of large, woody plants during the Devonian.

The present atmospheric partial pressure of $\mathrm{O}_{2}$ is approximately 500 times higher than that of $\mathrm{CO}_{2}$. Despite the lower solubility of oxygen than $\mathrm{CO}_{2}$, oxygen levels may be 25- to 30 -fold higher than $\mathrm{CO}_{2}$ levels at Rubisco's catalytic site. Thus, over evolutionary time, as $\mathrm{CO}_{2}$ levels have fallen and oxygen levels increased, Rubisco has evolved to discriminate between $\mathrm{CO}_{2}$ and $\mathrm{O}_{2}$, and modern $\mathrm{C}_{3}$ Rubisco has a discrimination ratio (specificity) of around 100:1. However, increases in Rubisco's $\mathrm{CO}_{2}$ affinity correlate with declines in the carboxylation rate, requiring an increased proportion of leaf nitrogen to be allocated to Rubisco, in order to maintain photosynthetic rates (Galmés et al. 2014a). This may have negative implications for whole plant nitrogen use efficiency, since approximately $50 \%$ of nitrogen in new leaves derives from the breakdown of Rubisco and other soluble proteins from senescent leaves (Mae and Ohira 1981; Mae 1986).

Drought causes stomatal closure. As $\mathrm{CO}_{2}$ in intercellular gas spaces is rapidly depleted under high light conditions, drought induced stomatal closure leads to an increase in photorespiration as the $\mathrm{O}_{2} / \mathrm{CO}_{2}$ ratio increases rapidly. Galmés et al. (2014b) found that Limonium species in which drought had little effect on $\mathrm{CO}_{2}$ availability at Rubisco's active site had lower $\mathrm{CO}_{2}$ specificities than species in which drought significantly reduced $\mathrm{CO}_{2}$ availability. As in other studies, a negative relationship existed between maximum carboxylation rate and specificity. As specificity increased, biomass accumulation increased, despite decreases in photosynthetic rates. Presumably this increase in biomass production was due to decreases in photorespiratory carbon losses.

Although generally seen as wasteful, photorespiration is thought to act as a mechanism by which excess light energy can be used, reducing photodamage to the chloroplast (André 2011). Even under moderate drought conditions, stomatal closure quickly depletes leaf $\mathrm{CO}_{2}$ levels, while sucrose phosphate synthase activity is repressed, which may lead to feedback repression of photosynthesis (Vassey et al. 1991). In the absence of photorespiration, a lack of capacity for NADPH consumption would cause increases in both Mehler reactiongenerated oxygen radicals and nonphotochemical quenching (Makino et al. 2002; Medrano et al. 2002). Given that most plants are probably under moderate stress most of the time, genetically engineered plants lacking oxygenase activity might exhibit higher levels of photodamage, reduced leaf lifespans, and reduced net carbon balance. It would seem that 
engineering an oxygenase-free Rubisco may not be viable within $\mathrm{a}_{3}$ architecture.

\subsubsection{Rubisco Concentration and N Allocation}

Photosynthetic rates at ambient $\mathrm{CO}_{2}$ levels correlate with leaf Rubisco concentration (Makino 2003). In grasses, Rubisco content increases rapidly during leaf emergence, reaching a maximum around full leaf expansion followed by a gradual decline until leaf death (Figure 41.2; Mae et al. 1983; Irving and Robinson 2006). In rice, even under high exogenous $\mathrm{N}$ supply conditions, approximately half of the nitrogen for new leaf growth comes from the remobilization of proteins from older leaves (Mae and Ohira 1981); thus, degradation of Rubisco in older leaves is necessary for the growth of new leaves. On the other hand, as leaf photosynthetic rates correlate with leaf Rubisco content (Makino et al. 1985), we might sensibly conclude that in order to maximize the photosynthetic rates of individual leaves, Rubisco degradation should be retarded, or synthesis maintained throughout the leaf lifespan. However, this would come at the expense of reduced rates of new leaf production.

Previous investigators have noted a correlation between leaf $\mathrm{N}$ content and the light environment of the canopy, allowing efficient distribution of nitrogen between leaves in a manner that increases canopy photosynthesis, compared to a uniform $\mathrm{N}$ distribution (Hirose and Werger 1987; Anten et al. 1995). This has been taken to suggest that plants have specific mechanisms for regulating leaf $\mathrm{N}$ content in a light-dependent manner (Grindlay 1997). Hikosaka (1996) grew the vine Ipomoea tricolor horizontally to prevent leaf shading, separating the effects of leaf age and light availability on nitrogen allocation, since older leaves tend to be lower in most canopies. At low $\mathrm{N}$ levels, older leaves contained significantly lower $\mathrm{N}$ levels than younger leaves, suggesting that leaf age may be a more important factor than light availability in determining leaf $\mathrm{N}$ contents. However, at high $\mathrm{N}$ levels, these differences disappeared, suggesting some plasticity under ideal conditions.

Hikosaka and Terashima (1995) demonstrated that the optimal partitioning of nitrogen into different photosynthetic components (e.g., Calvin-Benson cycle enzymes, chlorophyll and electron transport chain components) varies depending upon the light and nitrogen supply to the leaf. As leaves are part of a dynamic canopy, first exposed to full sunlight and with high levels of $\mathrm{N}$ influx, but later shaded with reduced $\mathrm{N}$ influx, we should expect to see changes in the balance of different protein levels through time, and perhaps inefficiencies, due to the leaves' limited ability for recycling and repartitioning nitrogen. At medium and high light levels (i.e., younger leaves at the top of the canopy), the optimal strategy

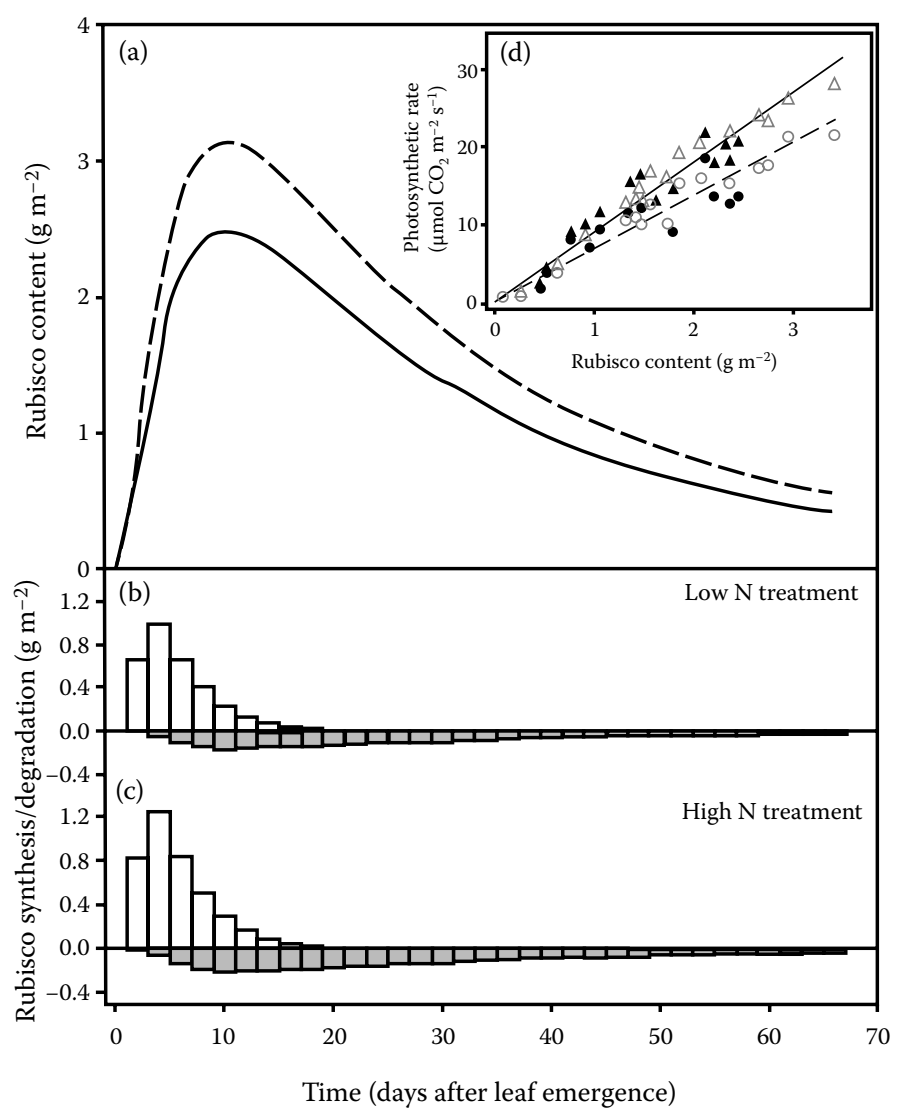

FIGURE 41.2 Rubisco content (a) and synthesis and degradation (b and c) through time in the twelfth leaf of rice plants fed with 1 or $3 \mathrm{mM}$ $\mathrm{NH}_{4} \mathrm{NO}_{3}$ (solid and dashed lines, respectively) modelled using the model of Irving and Robinson (2006) with an $a$ value of 3 , and a $b$ value of 0.004 , and (d) the photosynthetic rate at $1 \mathrm{mM}$ (closed symbols) or $3 \mathrm{mM}$ (open symbols), at $350 \mathrm{ppm} \mathrm{CO}_{2}$ and $500 \mathrm{mmol} \mathrm{photons} \mathrm{m}^{-2} \mathrm{~s}^{-1}$ (circles) or $2000 \mu \mathrm{mol}$ photons $\mathrm{m}^{-2} \mathrm{~s}^{-1}$ (triangles). (Data remodeled from Makino A et al., Planta 166:414-420, 1985.) 
is for leaves to invest a large fraction of their nitrogen into Rubisco, particularly in nitrogen-replete plants. However, at lower light intensities (i.e., older leaves, deeper in the canopy), and at lower leaf $\mathrm{N}$ levels, a lower proportion of nitrogen should be partitioned to Rubisco. In this context, the vesicular export of Rubisco from chloroplasts during senescence can be understood (Izumi et al. 2010). As the production of Rubiscocontaining bodies is suppressed by leaf carbohydrates, leaves lower in the canopy, which receive less light and produce less carbohydrate, may use leaf carbohydrate status as a signal to remobilize nitrogen for new leaf production.

At low $\mathrm{CO}_{2}$ levels, such as those that have dominated for the last 400,000 years (Petit et al. 1999), Rubisco's carboxylation capacity is not saturated (Makino et al. 1983), and Rubisco content is understood to limit photosynthesis (Makino et al. 1988). In accordance with this, a recent paper demonstrated $32 \%$ and $15 \%$ biomass increases in Rubisco overexpressing rice grown at 280 and $400 \mathrm{ppm}$ (ambient) $\mathrm{CO}_{2}$, respectively, while at $1200 \mathrm{ppm} \mathrm{CO}_{2}$ levels, no promotion of biomass production was noted. Conversely, in Rubisco antisense plants, biomass accumulation was significantly retarded compared to controls irrespective of $\mathrm{CO}_{2}$ levels (Sudo et al. 2014). Plants grown at elevated $\mathrm{CO}_{2}$ (e.g., in free-air $\mathrm{CO}_{2}$ enrichment [FACE] experiments) generally exhibit reduced leaf Rubisco concentrations, relative to controls (Moore et al. 1999). In Arabidopsis grown at 1000 ppm $\mathrm{CO}_{2}$, Rubisco protein content decreased by $34 \%$, and transcript abundances by $38 \%$ and $60 \%$ from $r b c S$ and $r b c L$, respectively (Cheng et al. 1998), although these results are not typical for all species. For example, Rubisco levels in pea, spinach, parsley, and maize are relatively unaffected by $\mathrm{CO}_{2}$ elevation (Moore et al. 1998). Reduced $\mathrm{N}$ investment in Rubisco may allow greater biomass production and more rapid plant development.

Anten et al. (1995) demonstrated that in order to maximize photosynthetic rates, nitrogen should be remobilized from older leaves to newer, younger leaves, higher in the canopy. Hikosaka and Terashima (1995) further showed that Rubisco should be a prime target of nitrogen remobilization from older to younger leaves. If anything, Anten et al. (1995) show us that nitrogen should be remobilized more rapidly from older leaves than it actually is, and the gradient in canopy $\mathrm{N}$ levels should be steeper. We might posit various explanations for this, for example, that the optimal $\mathrm{N}$ distribution is further shaped by the energy costs associated with leaf growth, protein synthesis, and degradation, or that the maintenance of $\mathrm{N}$ in older leaves represents some form of insurance against grazing damage. Either way, increasing plant growth rates seems to require increasing Rubisco levels, which seems difficult without substantially increasing $\mathrm{N}$ supply, or increasing $\mathrm{CO}_{2}$ levels at the site of carbon fixation.

\subsubsection{OPPORTUNITIES FOR IMPROVING Rubisco Performance}

Improving plant photosynthesis has been a long-held goal of plant molecular biologists. As noted, along with its carboxylase activity, Rubisco also functions as an oxygenase in photorespiration, costing the plant carbon, nitrogen, and energy, but providing a degree of protection against photodamage. Photorespiratory carbon losses are a particular problem for $\mathrm{C}_{3}$ plants, where primary assimilation of carbon dioxide is distributed among leaf mesophyll cells. While $\mathrm{C}_{3}$ plants dominate in temperate environments, under drought conditions, $\mathrm{C}_{4}$ plants have an advantage. In $\mathrm{C}_{4}$ plants, $\mathrm{CO}_{2}$ is assimilated by PEP carboxylase and shuttled to bundle sheath cells surrounding the leaf veins, where the $\mathrm{CO}_{2}$ is liberated and subsequently refixed by Rubisco. PEP carboxylase has a high affinity for $\mathrm{CO}_{2}$, allowing the maintenance of high $\mathrm{CO}_{2}$ levels at the active site of Rubisco, thus suppressing Rubisco's oxygenase activity. Suppression of photorespiration, for example, by growing $\mathrm{C}_{3}$ plants at reduced oxygen partial pressures, has long been known to lead to significant enhancement of both $\mathrm{CO}_{2}$ fixation rates and growth (Björkman 1966; Björkman et al. 1968).

$\mathrm{C}_{4}$ Rubiscos have maximum carboxylation rates up to double those in $\mathrm{C}_{3}$ plants allowing them to invest less nitrogen in Rubisco (Ghannoum et al. 2005). The highest maximum carboxylation rates, and thus lowest specificities, are found in cyanobacteria, which can take advantage of both the lower solubility of oxygen in water compared with $\mathrm{CO}_{2}$ (an effect that is exacerbated with depth) and carbon dioxide concentrating mechanisms (Raven 2000). A recent perspective (von Caemmerer et al. 2012) is optimistic about the possibility of the first $\mathrm{C}_{4}$ prototype rice plants within a few years. Although the technical challenges are great, we should consider that $\mathrm{C}_{4}$ has evolved more than 62 times in various flowering plant groups, including 24 times in the grasses alone (Studer et al. 2014).

In Flaveria, a single mutation (M309I) was key in reducing specificity and increasing the maximum carboxylation rate (Whitney et al. 2011), suggesting that the switch from $\mathrm{C}_{3}$-type to $\mathrm{C}_{4}$-type Rubisco may be relatively simpler than previously considered. Conversely, a recent paper using a modelling approach to explore the effect on mutations on the stability and activity of Rubisco found that $98.9 \%$ of amino acid substitutions had a moderate or highly destabilizing effect, while $1.1 \%$ of mutations were found to have a stabilizing effect (Studer et al. 2014). Most of these stabilizing mutations were close to the active site and generally would have a negative effect on enzyme function. Of ancestral mutations, 91.5\% were noted to have had minor effects on enzyme stability, suggesting that stability is a strong constraint on enzyme evolution. The evolution of $\mathrm{C}_{4}$ Rubisco required the presence of a strongly destabilizing mutation, which could then be followed up by a series of stabilizing mutations. The authors describe Rubisco as having evolved on a small island of stability, which raises fundamental questions about how far we can improve $\mathrm{C}_{3}$ Rubisco in a stepwise fashion.

Recently, Lin et al. (2014) successfully produced transgenic tobacco plants, containing functional Synechococcus elongatus Rubisco. S. elongatus Rubisco has a high catalytic rate-approximately $12 \mathrm{CO}_{2}$ molecules can be fixed per second, compared to 3 molecules per second for host tobacco Rubisco. The transgenic plants contained only $12-18 \%$ of 
the Rubisco levels found in wild-type tobacco plants, and $S$. elongatus Rubisco has a low affinity for $\mathrm{CO}_{2}(\mathrm{Km}$ value of $200 \mu \mathrm{M}$ compared to $6-12 \mu \mathrm{M}$ for $\mathrm{C}_{3}$ angiosperms); thus, they had to be grown at $9000 \mathrm{ppm} \mathrm{CO} \mathrm{CO}_{2}$ (Lin et al. 2014). It is clear that Synechococcus Rubisco could not be used in $\mathrm{C}_{3}$ plants under current environmental conditions; however, if expressed in a $\mathrm{C}_{4}$ architecture, or a $\mathrm{C}_{3}$ plant with a CCM, it might significantly increase photosynthetic rates, allowing the reallocation of significant amounts of $\mathrm{N}$ for new leaf growth.

Rubisco evolved in a high $\mathrm{CO}_{2}$, low $\mathrm{O}_{2}$ environment around 3.5 billion years ago. For $85 \%$ of its history, it has evolved in an environment with oxygen levels less than $10 \%$ of present levels, where its oxygenase activity would have presented little issue. However, in the last 500 million years, the evolution of large, woody plants, and the resulting vast increase in atmospheric oxygen, prompted the evolution of increased specificity for $\mathrm{CO}_{2}$. This increased specificity comes at the cost of the maximum carboxylation rate, requiring plants to partition up to one-third of leaf nitrogen to Rubisco. The evolution of $\mathrm{C}_{4}$ plants with higher maximum carboxylation rates allowed a reduced nitrogen allocation to Rubisco, which could be invested in new biomass production. Clearly, a path to increase the yield of many major $\mathrm{C}_{3}$ crops would be the development of $\mathrm{C}_{4}$ varieties, using cyanobacterial Rubisco, which might break the deadlock between nitrogen investment in photosynthetic proteins in living leaves, and the production of new leaves and increased biomass.

\subsection{INCREASING THE THERMOTOLERANCE OF RUBISCO ACTIVASE TO MAINTAIN HIGHER RUBISCO ACTIVITY UNDER HIGH TEMPERATURES}

The Rubisco catalytic sites must first be activated for $\mathrm{CO}_{2}$ fixation to take place (Figure 41.1). This requires the carbamylation of a lysine residue at the Rubisco catalytic site, allowing the binding of $\mathrm{Mg}^{2+}$ and ribulose-1,5-bisphosphate (RuBP). Rubisco activase facilitates carbamylation and the maintenance of Rubisco activity by removing inhibitors such as tight-binding sugar phosphates from Rubisco catalytic sites in an ATP-dependent manner (Spreitzer and Salvucci 2002; Portis 2003; Parry et al. 2008).

In many plant species, Rubisco activation state decreases at high temperatures (Crafts-Brandner and Salvucci 2000: Salvucci and Crafts-Brandner 2004a; Yamori et al. 2006, 2014; Yamori and von Caemmerer 2009). It has been reported that Rubisco deactivation at high temperature could be due to the insufficient activity of Rubisco activase to keep pace with the faster rates of Rubisco inactivation at high temperature because of its thermolability (Salvucci and CraftsBrandner 2004b). Reduced levels of Rubisco activase resulted in decreased photosynthetic rate at high temperature using mutants/transgenic plants in Arabidopsis (Salvucci et al. 2006), rice (Yamori et al. 2012), and tobacco (Yamori and von Caemmerer 2009). It has been reported that overexpression of maize Rubisco activase in rice stimulated Rubisco activation state and photosynthetic rate at high temperature (Yamori et al. 2012). In addition, transgenic Arabidopsis expressing thermotolerant Rubisco activase isoforms generated by either gene shuffling technology (Kurek et al. 2007) or chimeric Rubisco activase constructs (Kumar et al. 2009) exhibited greater photosynthetic rates, greater biomass production, and increased seed yields, compared with the wild-type plants. This suggests that Rubisco activase activity is a major limiting factor for photosynthesis under high temperature, and that engineering of Rubisco activase would be an efficient strategy to improve crop yield under high temperatures.

An additional vital role of Rubisco activase in the regulation of photosynthesis under fluctuating light has been reported recently (Yamori et al. 2012). At any leaf temperature, the speed by which Rubisco activation state and photosynthetic rate change following an increase in light intensity changed markedly faster in plants overexpressing maize Rubisco activase compared to wild-type rice. In addition, the parameter changed more slowly in antisense plants with reduced levels of Rubisco activase. Thus, a selective enhancement of Rubisco activase capacity would be also advantageous in natural environments where irradiance often fluctuates. Recently, the structure of Rubisco activase has been determined, providing insight into its interactions with Rubisco (Stotz et al. 2011) and its counterpart $\mathrm{CbbX}$ in red algae (Mueller-Cajar et al. 2011). The structural information coupled with the knowledge of regulation in Rubisco activase would contribute to improve its thermostability and catalytic properties.

\subsection{INCREASING THE $\mathrm{CO}_{2}$ CONCENTRATION AROUND RUBISCO}

Rubisco is a dual-function enzyme that can use either $\mathrm{CO}_{2}$ or $\mathrm{O}_{2}$ to carboxylate or oxygenate its primary substrate $\mathrm{RuBP}$, two processes that have been termed photosynthesis and photorespiration (Bauwe et al. 2010). While photosynthesis results in a net fixation of $\mathrm{CO}_{2}$, the photorespiratory pathway requires ATP and releases previously fixed $\mathrm{CO}_{2}$. The rate of photorespiration is affected by the concentration of $\mathrm{CO}_{2}$ in the chloroplast $\left(C_{\mathrm{c}}\right)$ relative to the $\mathrm{O}_{2}$ concentration and increases with increasing temperature. At current atmospheric $\mathrm{CO}_{2}$ concentrations and a temperature of $30^{\circ} \mathrm{C}$, the rate of photorespiratory $\mathrm{CO}_{2}$ release from the mitochondria is approximately $25 \%$ of the rate of net $\mathrm{CO}_{2}$ assimilation (Sage et al. 2012). Increasing $C_{\mathrm{c}}$, and thereby minimizing photorespiration, is therefore a promising target to increase the rate of photosynthesis in crops. In $\mathrm{C}_{3}$ plants, $C_{\mathrm{c}}$ is determined not only by the atmospheric $\mathrm{CO}_{2}$ concentration but also by the resistance for $\mathrm{CO}_{2}$ to diffuse from the outside of the leaf to the chloroplast (Figures 41.1 and 41.3). $\mathrm{CO}_{2}$ diffusion to the chloroplast can be influenced by modifying the conductance through the stomata $\left(g_{s}\right)$ to the intercellular air space (IAS), either by increasing the stomatal density (Tanaka et al. 2013) or by preventing stomatal closure (Kusumi et al. 2012). Both approaches resulted in increased rates of net $\mathrm{CO}_{2}$ assimilation, albeit at the cost of higher transpiration rates and lower water-use efficiency. 
An alternative approach addresses the other major diffusion resistance for $\mathrm{CO}_{2}$ from the intercellular air space into the mesophyll cell chloroplasts. In contrast to modifying $g_{\text {s }}$, increasing mesophyll conductance $\left(g_{\mathrm{m}}\right)$ does not negatively affect water-use efficiency. A large proportion of $g_{\mathrm{m}}$ has been shown to be dependent on cell wall thickness, meaning that $\mathrm{CO}_{2}$ diffusion can potentially be improved by modifying plants to have smaller mesophyll cells with thinner cell walls (Terashima et al. 2011). Plants with smaller cells not only can afford to have thinner cell walls but also result in an increased mesophyll surface area. A larger surface area exposed to the IAS can be occupied by more chloroplasts pressing against the cell walls, which again aids $\mathrm{CO}_{2}$ diffusion into the chloroplast (Evans et al. 1994), while at the same time impairs diffusion of photorespiratory $\mathrm{CO}_{2}$ out into the IAS (Figure 41.3; Busch et al. 2013).

The second important component of $g_{\mathrm{m}}$ involves the diffusion of $\mathrm{CO}_{2}$ through the plasma and chloroplast membranes (Evans et al. 2009), and a number of approaches are under way to increase the chloroplastic $\mathrm{CO}_{2}$ concentration in $\mathrm{C}_{3}$ plants by increasing the membrane permeability for $\mathrm{CO}_{2}$. Aquaporins that are permeable to $\mathrm{CO}_{2}$ are proteins that assist the $\mathrm{CO}_{2}$ diffusion through the membranes by providing pores through which $\mathrm{CO}_{2}$ can be channeled (Kaldenhoff 2012). It has been shown that the disruption to the aquaporin AtPIP1;2 gene limits $\mathrm{CO}_{2}$ transport across the membrane (Heckwolf et al. 2011), while the overexpression of different aquaporin genes resulted in increased $g_{\mathrm{m}}$ (Hanba et al. 2004;
Flexas et al. 2006). Modifying the membrane permeability for bicarbonate $\left(\mathrm{HCO}_{3}^{-}\right)$can also facilitate the transport of $\mathrm{CO}_{2}$ across the membrane. Adding cyanobacterial $\mathrm{HCO}_{3}^{-}$ transporters to the chloroplast envelope of $\mathrm{C}_{3}$ plants would provide a parallel route for inorganic carbon to enter the chloroplast, in addition to the diffusion of dissolved $\mathrm{CO}_{2}$ (Price et al. 2011, 2013). Lastly, the enzyme carbonic anhydrase (CA) plays a role in facilitating the diffusion of $\mathrm{CO}_{2}$ throughout the aqueous phase of the chloroplast stroma by interconverting between $\mathrm{CO}_{2}$ and $\mathrm{HCO}_{3}^{-}$and providing a more even distribution of $\mathrm{CO}_{2}$ throughout the chloroplast (Evans et al. 2009). It has been suggested that the amount of CA found in plants is somewhat limiting the conductance in the stroma of $\mathrm{C}_{3}$ crops, opening up the possibility for improving this aspect by molecular engineering (Makino et al. 1992; Tholen and Zhu 2011).

In addition to decreasing the resistance for $\mathrm{CO}_{2}$ to diffuse into the chloroplast from the IAS, advances have been made to engineer plants that can make better use of the $\mathrm{CO}_{2}$ released from photorespiration. The introduction of a bacterial pathway for glycolate metabolism into the chloroplasts of Arabidopsis thaliana creates a photorespiratory bypass that releases $\mathrm{CO}_{2}$ directly into the chloroplast and thereby increases $C_{\mathrm{c}}$ (Kebeish et al. 2007; Maier et al. 2012). However, this approach might be limited to minor benefits in high yielding $\mathrm{C}_{3}$ crop plants that already trap a high proportion of photorespiratory $\mathrm{CO}_{2}$ by having a high chloroplast cover of the cell wall space facing the IAS (Busch et al. 2013).

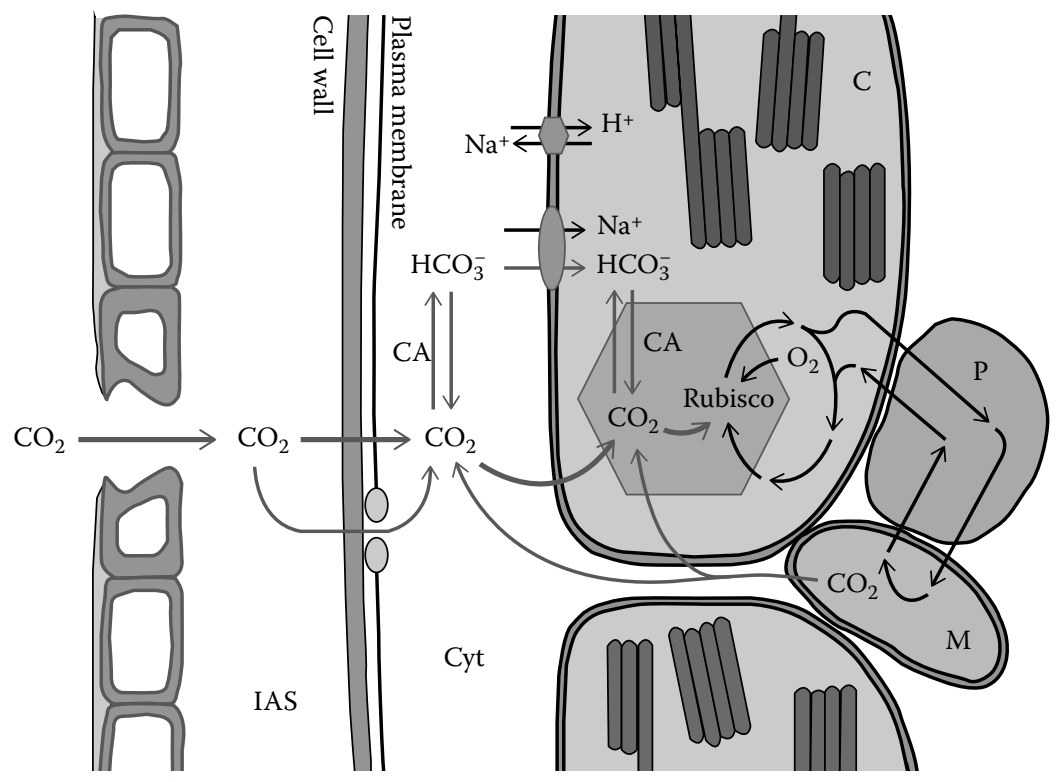

FIGURE 41.3 Schematic representation of mechanisms for concentrating $\mathrm{CO}_{2}$ around Rubisco. The diagram shows $\mathrm{CO}_{2}$ moving from the outside of the leaf through the stomatal pore to the intercellular air space (IAS), from where it diffuses through the cell wall and plasma membrane into the cytosol. $\mathrm{CO}_{2}$ permeable aquaporins may aid the transport of $\mathrm{CO}_{2}$ into the cytosol (Cyt) of the mesophyll cell. The transport of $\mathrm{CO}_{2}$ into the chloroplast (C) could be improved by introducing a cyanobacterial $\mathrm{HCO}_{3}^{-}$transporter into the chloroplast envelope, creating an additional pathway for $\mathrm{CO}_{2}$ entering the chloroplast. The addition of a Rubisco and CA-containing carboxysome (represented by the hexagonal structure) could further increase the $\mathrm{CO}_{2}$ concentration around Rubisco, minimizing the rate of photorespiration. Photorespiration involves peroxisomes $(\mathrm{P})$ and mitochondria $(\mathrm{M})$ and results in the release of $\mathrm{CO}_{2}$. Capturing this $\mathrm{CO}_{2}$, either by minimizing the diffusion out into the IAS or by engineering a pathway that results in the release of photorespiratory $\mathrm{CO}_{2}$ directly into the chloroplast, also could increase the $\mathrm{CO}_{2}$ concentration around Rubisco. (Adapted from Price GD et al., Plant Physiology 155: 20-26, 2011.) 
A substantial increase in the $\mathrm{CO}_{2}$ concentration around Rubisco may be achieved by installing a carbon concentrating mechanism (CCM) in $\mathrm{C}_{3}$ crop plants. Cyanobacteria have evolved a single-cell CCM, in which Rubisco is encapsulated in a cellular compartment known as carboxysome (Price et al. 2011). In the carboxysomes, the $\mathrm{CO}_{2}$ concentration is enriched up to 1000 -fold, significantly reducing the rate of photorespiration. This is achieved by the conversion of $\mathrm{CO}_{2}$ to $\mathrm{HCO}_{3}^{-}$, which can be accumulated in the cell, by $\mathrm{CA}$ at the cyanobacterial thylakoid membrane, combined with the CA-mediated $\mathrm{CO}_{2}$ release in the carboxysome. A fully functioning cyanobacteriallike $\mathrm{CCM}$ in the $\mathrm{C}_{3}$ chloroplast would require the introduction of $\mathrm{HCO}_{3}^{-}$transporters, adjustments in the expression of chloroplastic $\mathrm{CA}$ in order to allow $\mathrm{HCO}_{3}^{-}$accumulation, and the establishment of a Rubisco- and CA-containing compartment, such as the carboxysome (Figure 41.3) (Price et al. 2011, 2013).

$\mathrm{C}_{4}$ plants evolved a two-cell $\mathrm{CCM}$, where $\mathrm{CO}_{2}$ is initially fixed in the mesophyll cells by the enzyme phosphoenolpyruvate carboxylase (PEPC) to produce a $\mathrm{C}_{4}$ acid. The organic acid diffuses to the specialized gas-tight bundle-sheath cells, where it is decarboxylated, resulting in significantly increased $\mathrm{CO}_{2}$ concentrations around Rubisco. In addition to higher yields, the benefits of this photosynthetic pathway include an improved nitrogen- and water-use efficiency (Sage 2004). Currently, considerable efforts are undertaken to engineer features of the complex $\mathrm{C}_{4}$ pathway into $\mathrm{C}_{3}$ crops like rice (Covshoff and Hibberd 2012; von Caemmerer et al. 2012). Challenges associated with this approach include morphological adjustments, such as the establishment of a Kranz(-like) anatomy, as well as introducing the $\mathrm{C}_{4}$ biochemistry into $\mathrm{C}_{3}$ leaves (Covshoff and Hibberd 2012).

Another CCM that is based on a prefixation step of $\mathrm{CO}_{2}$ into $\mathrm{C}_{4}$ acids is the crassulacean acid metabolism (CAM). Here, the initial $\mathrm{CO}_{2}$ fixation step by PEPC and the final fixation by Rubisco are not spatially separated like in $\mathrm{C}_{4}$ plants, but both steps are located in the same cell type and are separated temporally. CAM plants take up $\mathrm{CO}_{2}$ during the night and store it as $\mathrm{C}_{4}$ acid in the vacuole, with the decarboxylation step and subsequent $\mathrm{CO}_{2}$ fixation by Rubisco occurring during the day (Dodd et al. 2002). By shifting the $\mathrm{CO}_{2}$ uptake to the nighttime and keeping stomata largely closed during the day, the plant can achieve high rates of photosynthesis with a water-use efficiency superior to both $\mathrm{C}_{3}$ and $\mathrm{C}_{4}$ plants. Early stages of attempting to move the CAM metabolism into $\mathrm{C}_{3}$ plants have been reported, with the aim of improving plant productivity under water-limited conditions (Borland et al. 2014; DePaoli et al. 2014).

\subsection{ENHANCING THE RATE OF CHLOROPLAST ELECTRON TRANSPORT IN THE THYLAKOID MEMBRANES}

ATP and NADPH generated during photosynthetic electron transport in the thylakoid membranes are used to power photosynthetic carbon reduction. In a future high $\mathrm{CO}_{2}$ world, the rate of $\mathrm{CO}_{2}$ assimilation would be limited by the rate of
RuBP regeneration in the Calvin-Benson cycle (Farquhar et al. 1980), which in turn is limited by the chloroplast electron transport capacity (Yamori et al. 2011). The cytochrome $b_{6} / f$ complex has a unique role in chloroplast electron transport (Figure 41.1), as it can act in both linear electron transport (production of ATP and NADPH) and cyclic electron transport (ATP generation only) (Yamori et al. 2015). There is a strong linear relationship between chloroplast electron transport rate and cytochrome $b_{6} / f$ complex content at any leaf temperature (Yamori et al. 2011). Thus, it could be a suitable target for genetic manipulation to improve photosynthesis and thus plant yield.

Figure 41.4 shows the Z-scheme of photosynthetic electron transfer from water to $\mathrm{NADP}^{+}$and approximate estimated times for various steps in the scheme. It has been proposed that photosynthetic electron transport could be mostly limited by the reduction and reoxidation of the diffusible components (i.e., plastoquinone, plastocyanin, and ferredoxin) that interconnect the membrane-bound complexes (Yamori et al. 2008). Previous experiments with antisense lines have shown that even a moderate reduction of the amounts of chloroplastic ferredoxin NADP $(\mathrm{H})$ oxidoreductase (FNR), which catalyzes the terminal reaction of the photosynthetic electron transport chain by transferring electrons from reduced ferredoxin to $\mathrm{NADP}^{+}$, has a negative impact on photosynthetic rate under both low and high light conditions (Hajirezaei et al. 2002). However, overexpression of FNR (Rodriguez et al. 2007) or ferredoxin (Yamamoto et al. 2006) did not increase photosynthesis or plant growth in tobacco, irrespective of growth light conditions. Electron transfer between the cytochrome $\mathrm{b}_{6} / \mathrm{f}$ complex and photosystem I is exclusively mediated by plastocyanin in higher plants, whereas in many algae, it is mediated by cytochrome $c 6$. Variations in plastocyanin levels have been reported to coincide with variations in photosynthetic electron transport activity (Burkey 1994; Burkey et al. 1996; Schöttler et al. 2004), leading to the conclusion that the plastocyanin pool size is limiting for photosynthetic electron transport. Two homologous plastocyanin isoforms are encoded by the genes PETE1 and PETE2 in the nuclear genome of A. thaliana. An analysis of knockout plants for PETE1 and PETE2 in A. thaliana showed that the plastocyanin content can be significantly decreased without apparent changes in the photosynthetic rate, suggesting that the concentration of plastocyanin is not limiting for photosynthetic electron transport rate (Pesaresi et al. 2009). However, overexpression of either PETE1 or PETE2 results in an increase in biomass production (Pesaresi et al. 2009). Thus, there is a discrepancy between experimental data of knockout and overexpression lines. The introduction of a parallel electron carrier between cytochrome $b_{6} / f$ complex and photosystem I through the expression of an algal cytochrome $c 6$ gene in A. thaliana resulted in an enhancement of electron transport rate and thus NADPH and ATP production, leading to enhanced plant growth (Chida et al. 2007). This important evidence indicates that plastocyanin could be a suitable target for genetic manipulation to improve electron transport and thus plant yield. 


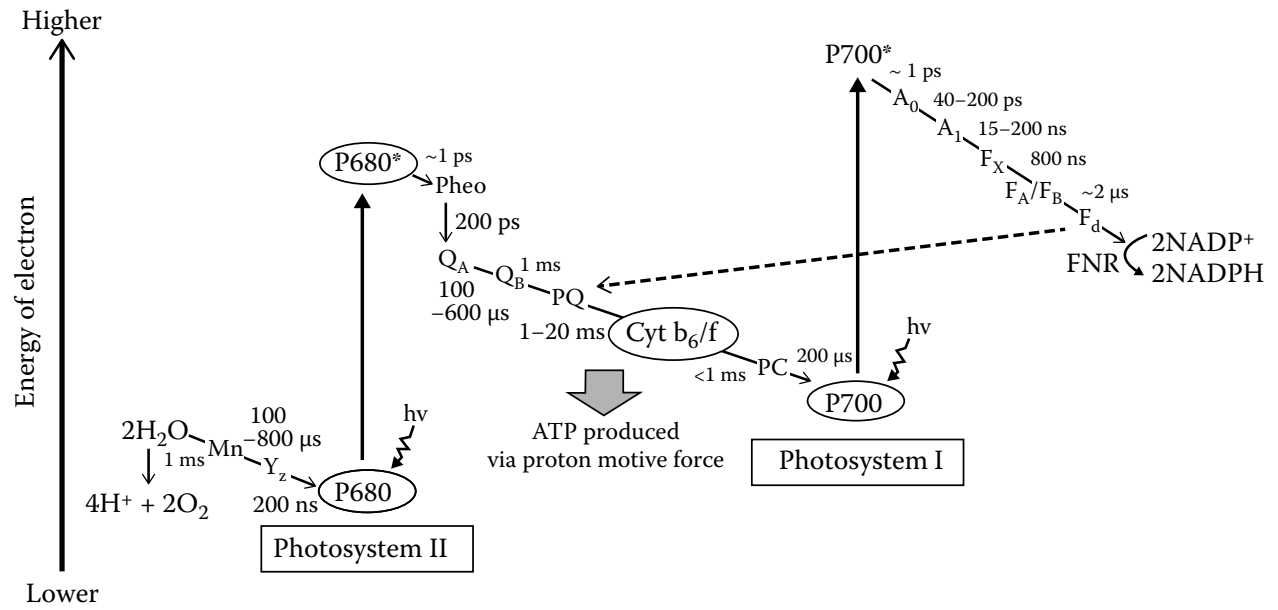

FIGURE 41.4 Scheme of photosynthetic electron transport from $\mathrm{H}_{2} \mathrm{O}$ to $\mathrm{NADP}^{+}$, leading to the release of $\mathrm{O}_{2}$, the reduction of $\mathrm{NAD}^{+}$to $\mathrm{NADPH}$, and production of ATP via proton motive force. Estimated times for various steps in the scheme are also noted on the figure. Mn: Mn cluster; Yz: tyrosine-161 on D1 protein; P680: the reaction center of photosystems II (PS II); P680*: the excited P680; Pheo: the primary electron acceptor of PS II; $\mathrm{Q}_{\mathrm{A}}$ : the primary plastoquinone electron accepter of PS II; $\mathrm{Q}_{\mathrm{B}}$ : the secondary plastoquinone electron acceptor of PS II; PQ: plastoquinone pool; Cyt $b_{6} / f$ : cytochrome $b_{6} / f$ complex; PC: plastocyanin; P700: the reaction center of photosystem I (PS I); P700*: the excited P700; $\mathrm{A}_{0}$ : primary electron acceptor of PS I; $\mathrm{A}_{1}$ : secondary electron acceptor of PS I; $\mathrm{F}_{\mathrm{X}}, \mathrm{F}_{\mathrm{A}}$, and $\mathrm{F}_{\mathrm{B}}$ : 3 different iron sulfur centers; $F_{d}$ : ferredoxin; FNR: ferredoxin-NADP reductase. The straight lines show linear electron transport, while the dashed line shows cyclic electron transport around PS I. (Modified from Govindjee, Chlorophyll a fluorescence: A bit of basics and history, In: G.C. Papageorgiou, Govindjee (Eds.), Chlorophyll a Fluorescence: A Signature of Photosynthesis, Kluwer Academic Publishers, Dordrecht, pp. 1-42, 2004.)

There have been other reports that documented an enhancement of plant biomass by genetic manipulation of photosynthetic electron transport. In the plant cell, NADP is mainly located in the chloroplast, where $\mathrm{NADP}^{+}$functions as the final electron acceptor of the photosynthetic electron transport chain (Wigge et al. 1993). NAD kinase regulates NAD(H)/ $\mathrm{NADP}(\mathrm{H})$ balance through its catalysis of NAD phosphorylation in the presence of ATP (Kawai and Murata 2008). In A. thaliana, one of the NADK isoforms localized in the chloroplast (NADK2; Chai et al. 2005) catalyzes a key step in the regulation of the NAD/NADP ratio (Kawai and Murata 2008). It succeeded in enhancing electron transport and $\mathrm{CO}_{2}$ assimilation rates by overexpression of Arabidopsis chloroplastic $N A D K$ (AtNADK2) in rice (Takahara et al. 2010). Moreover, the controlled up-regulation of Arabidopsis chlorophyllide $a$ oxygenase (CAO), involved in chlorophyll $b$ biosynthesis, in tobacco has been shown to enhance electron transport rates, $\mathrm{CO}_{2}$ assimilation, and plant biomass by co-modulating the expression of different thylakoid membrane proteins (Biswal et al. 2012). In addition, plants with a mutation in TAP38, an enzyme involved in dephosphorylation of light-harvesting complex of photosystem II, exhibited increased photosynthetic electron flow, leading to enhancement of plant growth under low light conditions (Pribil et al. 2010).

In situations where the electron transport rate is limited by the amount of available light that can be absorbed by the plant, increased light harvesting might boost photosynthetic productivity. Land plants utilize chlorophyll $a$ and $b$, which absorb light in the visible part of the solar spectrum of about 400-700 nm. Chlorophyll $d$ used by Acaryochloris (Miyashita et al. 1996) and chlorophyll $f$ discovered recently in the cyanobacterial communities of stromatolites (Chen et al. 2010) have red-shifted absorption spectra that enable their host organisms to perform oxygenic photosynthesis at the much longer wavelengths of 700-750 nm, which are inaccessible to other organisms. Introducing these chlorophylls into higher plants to supplement or replace the existing chlorophylls could potentially increase the amount of usable photon flux by up to $19 \%$ (Chen and Blankenship 2011). Since the photosynthetic electron transport chain provides energy and reducing equivalents for the reduction of fixed $\mathrm{CO}_{2}$ to carbohydrates in the Calvin-Benson cycle as well as for nitrogen assimilation and other processes, genetic manipulation of photosynthetic electron transport could be a candidate to improve the entire photosynthetic system, and thus plant yield.

\subsection{ENHANCING THE ACTIVITY OF CALVIN-BENSON CYCLE ENZYMES}

The Calvin-Benson cycle utilizes ATP and NADPH from photosynthetic electron transport to fix $\mathrm{CO}_{2}$ into carbon skeletons that are used for sucrose and starch production (Figure 41.1). The Calvin-Benson cycle also supplies intermediates to a lot of other pathways in the chloroplast, including the shikimate pathway for the biosynthesis of amino acids and lignin, isoprenoid biosynthesis, and precursors for nucleotide metabolism and cell wall synthesis (Lichtentahler 1999). This cycle comprises 11 different enzymes, catalyzing 13 reactions, and is initiated by Rubisco (Figure 41.5; Raines 2003). Four enzymes are regulated by thioredoxins: GAPDH, FBPase, SBPase, and PRK. Two of the 11 enzymes catalyze reversible reactions: aldolase and transketolase. 


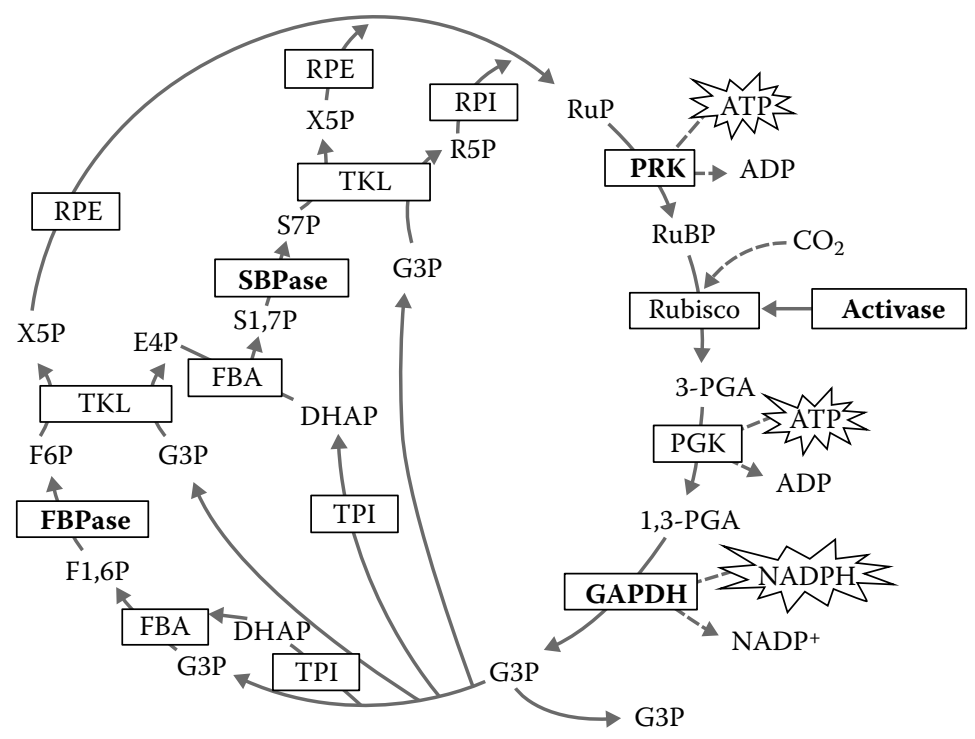

FIGURE 41.5 Scheme of the Calvin-Benson cycle. The Calvin-Benson cycle is the primary pathway for carbon fixation, and this cycle has 13 reaction steps catalyzed by 11 enzymes in the chloroplasts in higher plants. <Enzymes> Rubisco: ribulose-1,5-bisphosphate carboxylase/ oxygenase; PGK: phosphoglycerate kinase; GAPDH: glyceraldehyde-3-phosphate dehydrogenase; TPI: triose phosphate isomerase; FBA: fructose-1,6-bisphosphate aldolase; FBPase: fructose-1,6-bisphosphatase; TKL: transketolase; SBPase: sedoheptulose-1,7-bisphosphatase; RPE: ribulose-5-phosphate 3-epimerase; RPI: ribose-5-phosphate isomerase; PRK: phosphoribulokinase. <Metabolites> RuBP: ribulose1,5-bisphosphate; 3-PGA: 3-phosphoglycerate; 1,3-PGA: 1,3-bisphosphoglycerate; G3P: glyceraldehyde-3-phosphate; DHAP: dihydroxyacetone phosphate; F1,6P: fructose-1,6-bisphosphate; F6P: fructose-6-phosphate; X5P: xylulose-5-phosphate; E4P: erythrose-4-phosphate; S1,7P: sedoheptulose-1,7-bisphosphate; S7P: sedoheptulose-7-phosphate; R5P: ribose-5-phosphate; RuP: ribulose-5-phosphate. Four enzymes are regulated by thioredoxins: GAPDH, FBPase, SBPase, and PRK. Some proteins that control the activity of Calvin-Benson cycle enzymes are also regulated by thioredoxins (i.e., Rubisco activase and CP12, which forms a complex with PRK and GAPDH). (Modified from Michelet, L. et al., Frontiers in Plant Science 4: 470, 2013.)

To understand how metabolic fluxes in photosynthesis reactions are determined, metabolic flux control analysis has been examined (Woodrow 2009). Enzymes are assigned a control coefficient (between 0 and 1), which is a measure of the degree to which the flux is sensitive to changes in enzyme concentration. Flux control analyses using antisense plants for various Calvin-Benson cycle enzymes revealed a high control coefficients for Rubisco activity on photosynthetic rate at ambient $\mathrm{CO}_{2}$ concentrations and also sedoheptulose-1,7-bisphosphatase (SBPase) at high $\mathrm{CO}_{2}$ concentrations, but low control coefficients for the other Calvin-Benson cycle enzymes (Raines 2011). It has been reported that the photosynthetic rate at high light is sensitive to SBPase activity (Harrison et al. 1998; Ölcer et al. 2001). Moreover, photosynthesis and biomass production were improved by overexpression of cyanobacterial fructose-1,6-bisphosphatase and sedoheptulose1,7-bisphosphatase (FBPase/SBPase) in tobacco (Miyagawa et al. 2001). The subsequent research separated the effects of FBPase and SBPase by enhancing the activity of each one separately (Tamoi et al. 2006), showing a $25 \%$ rise in photosynthetic rate in response to increases in SBPase of between $60 \%$ and $330 \%$. A smaller but significant $15 \%$ rise in $\mathrm{A}_{\text {sat }}$ was observed in response to a $130 \%$ rise in FBPase. Therefore, they concluded that the photosynthetic rate was apparently sensitive to both FBPase and SBPase activity at all irradiances. It has been reported that photosynthesis and biomass production are also improved by overexpression of SBPase in rice (Feng et al. 2007) and in tobacco (Lefebvre et al. 2005). In addition, transgenic tobacco plants overexpressing SBPase from A. thaliana exhibited enhanced photosynthetic rate and biomass production when grown at $585 \mathrm{ppm} \mathrm{CO}_{2}$ in FACE experiments (Rosenthal et al. 2011). These reports provide evidence that SBPase is a major limiting factor for the Calvin-Benson cycle and thus photosynthesis, and that engineering of SBPase would be an efficient strategy to improve photosynthetic rate and crop yield especially in a future high $\mathrm{CO}_{2}$ world. The impact of FBPase on photosynthesis has not been brought to light yet, since the study of transgenic potato plants with reduced amounts of FBPase revealed that FBPase has a small control coefficient (Kossman et al. 1994). Further studies are needed to clarify the impact of FBPase on photosynthesis and plant growth.

There is a view among researchers in flux control analysis that enzymes catalyzing the reversible reactions of photosynthesis should not be flux limiting. However, nonregulated enzymes catalyzing reversible reactions, aldolase and transketolase, exerted significantly higher flux control for photosynthesis. In the first study, the photosynthetic rate of antisense potato plants with varying amounts of plastid aldolase was examined (Haake et al. 1998, 1999). Moderate reductions in aldolase activity were shown to cause significant reductions in photosynthetic rate and plant growth. Moreover, transgenic Arabidopsis and tobacco plants overexpressing plastidial aldolase exhibited enhanced photosynthetic rate, seed 
yield, and biomass production (Hatano-Iwasaki and Ogawa 2012; Uematsu et al. 2012). Also, experimental evidence has shown that small decreases in plastid transketolase activity in antisense tobacco transformants have dramatic effects on photosynthesis (Henkes et al. 2001). These studies confirm the rate-limiting nature of plastid aldolase and transketolase, and reveal its role in determining carbon flux in the CalvinBenson cycle.

Taken together, the manipulation of SBPase and aldolase (and possibly transketolase) levels in chloroplasts could increase photosynthetic capacity and could be used as a novel biotechnological tool to produce crops with high yield. Since increased accumulation of foliar carbohydrates has been shown to limit photosynthetic rate (Leakey et al. 2009), it should be noted that carbohydrate export from the source (leaves) to its utilization in sink tissues (seed, stem, roots, etc.) could also be an important target for enhancing photosynthesis that has remained unexplored.

\subsection{ENHANCING THE CAPACITY OF PHLOEM CARBOHYDRATE TRANSPORT AND CARBON UTILIZATION}

Accumulation of nonstructural carbohydrates in mature Phaseolus vulgaris leaves is known to cause photosynthetic repression (Araya et al. 2006). Although in several species soluble sugars suppress the expression of photosynthetic genes (Pego et al. 2000), Araya et al. (2006) noted a decrease in the Rubisco large subunit concentration only at the final time point measured, and no difference in LHCII levels between control and plants fed with $20 \mathrm{mM}$ sucrose solution, suggesting that any repression was not due to differences in leaf photochemistry. Conversely, Cheng et al. (1998) noted a 35-40\% decrease in $r b c L$ transcript- the gene encoding the Rubisco large subunit-in Arabidopsis plants grown at elevated $\mathrm{CO}_{2}$.

Conventionally, it is considered that the main drivers of stomatal aperture are water availability, light intensity, vapor pressure deficit, and intercellular $\mathrm{CO}_{2}$ concentration. However, recent evidence suggests that leaf carbon balance, which is at least partially mediated by phloem loading of carbohydrates produced in photosynthesis, can have an effect at levels comparable to hydraulic limitation (Nikinmaa et al. 2013). Assimilate transport in the phloem requires a hydrostatic gradient between photoassimilate sources (i.e., leaves) and sinks (e.g., roots and growing tissues). Phloem draws water from the xylem at sugar loading sites, thus competing directly with leaf tissues for water. High levels of sugar loading can lead to a decrease in flux rates due to increases in phloem sap viscosity (Hölttä et al. 2009), thus leading to a buildup in assimilate levels in the leaves, photosynthetic suppression, stomatal closure, and photorespiration. Conversely, high transpiration rates may also decrease water availability for phloem transport, leading to leaf carbohydrate accumulation (Hölttä et al. 2006).

Under drought conditions, sugars accumulate in the root phloem sap to counter the osmotic potential of the xylem.
Decreased sugar gradient between the leaves and the roots, and increased phloem sap viscosity, further decreases carbohydrate efflux from the leaves (Nikinmaa et al. 2013; Sevanto 2014). Carbohydrate build-up in leaves has been shown to reduce the production of Rubisco-containing bodies, which are important in the degradation of Rubisco in senescent leaves (Izumi et al. 2010), presumably since carbohydrate build-up is a signal that the leaf has sufficient light available for photosynthesis. Thus, carbohydrate build-up in leaves may delay leaf senescence, although it also tends to repress photosynthesis. Leaf-derived carbohydrates are also required for the production of new tissues (Lattanzi et al. 2005; Carvalho et al. 2006), but it is unclear whether carbon is limiting for leaf production for most plants under natural conditions.

Clearly, the loading and efficient transport of carbohydrates by the phloem have implications, both positive in terms of the potential for increased leaf lifespan and negative in terms of stomatal limitation, and potentially increased photorespiration. However, the balances of these factors are far from clear. Furthermore, it is presently unclear how much genetic variability exists for phloem transport characteristics, making a clear evaluation for its potential in improving crop yields impossible.

\subsection{INCREASING CROP YIELD BY OPTIMIZING PHOTOSYNTHESIS ON THE CANOPY LEVEL}

Improving photosynthesis to increase food production ultimately means maximizing the photosynthetic efficiency of a crop canopy rather than the individual plant. Canopy photosynthetic $\mathrm{CO}_{2}$ uptake is integrated across the plant from the sunlit leaves that are above light saturation to the shaded leaves that operate below their full capacity. The ideal crop plant architecture should optimize the light-use efficiency at the leaf level while maximizing the amount of absorbed solar radiation by the canopy per unit ground area (Zhu et al. 2010). Several ways have been proposed for how to alter plant architecture and biochemistry in order to achieve the highest conversion efficiency of solar radiation to biomass. This includes distributing the solar radiation more evenly throughout the canopy as well as matching the photosynthetic capacity at different layers within the canopy to the available light (Zhu et al. 2010). Two main approaches are employed to distribute sunlight more evenly throughout the canopy: adjusting the leaf angle of the plant and modifying the leaf chlorophyll content, both with the aim to reduce the light absorption of the leaves at the top of the canopy and to optimize the light penetration to the leaves lower in the canopy (Figure 41.6).

Light absorption by the canopy varies with, among other things, the angle of the leaves and the leaf area per unit ground, or leaf area index (LAI). The leaf angle, at which the interception of daily incident solar radiation is maximized, depends on LAI. Early in the growing season when LAI is low, maximum light interception is achieved in canopies with horizontal leaves covering a large proportion of the ground 


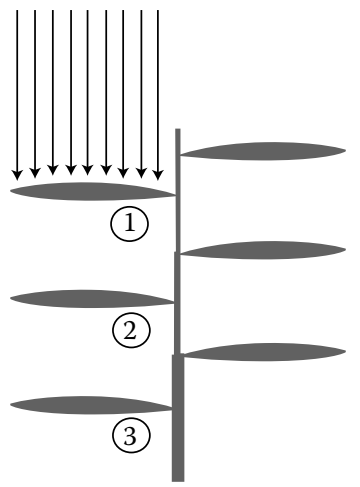

(a)

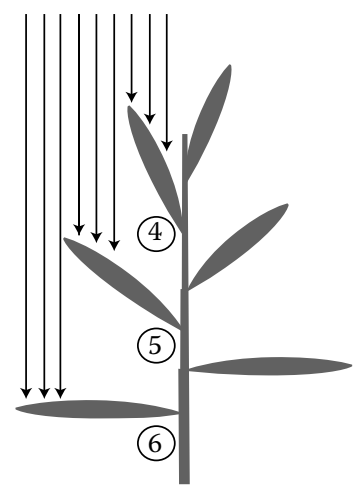

(b)

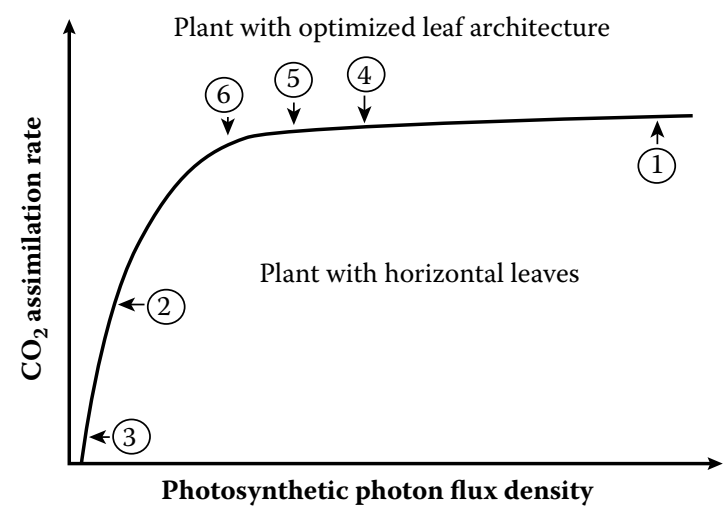

(c)

FIGURE 41.6 The effect of plant architecture on the $\mathrm{CO}_{2}$ assimilation rate of leaves in a crop canopy. (a) Plants with mostly horizontal leaves absorb most of the incoming solar radiation in the upper layer of the canopy. While these leaves have to dissipate the majority of the absorbed photosynthetic photon flux density as heat, the shaded layers of the lower canopy operate below light saturation. (b) A plant with optimized leaf architecture and more erect leaves in the upper canopy. A larger fraction of incoming solar radiation can penetrate to the lower canopy, bringing all leaves of the canopy closer to the minimum PPFD, at which $\mathrm{CO}_{2}$ assimilation is saturated (c). Similarly, a reduced amount of chlorophyll in the upper canopy facilitates a more even distribution of solar radiation throughout the canopy. (Modified from Long SP et al., Plant, Cell \& Environment 29: 315-330, 2006.)

area. However, for canopies with an LAI above 2, horizontal leaves at the upper layers of the canopy would be exposed to light intensities above saturation and at the same time shade the leaves in the lower layers (Long et al. 2006). An arrangement where the plant has leaves at a more vertical angle in the upper canopy, transitioning to horizontal leaves in the lower canopy, allows for a more even distribution of the incident solar radiation later in the growing season. Erect leaves that increase light capture and improve light distribution in dense canopies have been shown to increase yield in several species (Lambert and Johnson 1978; Sakamoto et al. 2006). Although our knowledge of the mechanisms that control plant architecture are still rudimentary, some progress has been made on determining what mechanisms influence leaf angle. The control of leaf and branch angle is a complex quantitative trait, and genes involved have been identified in several species, including rice ( $\mathrm{Li}$ et al. 2007), maize (Zhang et al. 2014), and Arabidopsis (Yoshihara et al. 2013).

Similar to the effects of plant architecture, a canopy that reduces light absorption in the top layers by minimizing the chlorophyll antennae will let more radiation penetrate to the lower layers and thereby distribute the light more evenly throughout the canopy (Melis 2009; Ort et al. 2011). This has been shown to work effectively in algae mass cultures, where cells with truncated light-harvesting chlorophyll antenna were able to significantly increase biomass production compared to normally pigmented cells by having improved light-use efficiency (Melis et al. 1999). In crop species, promising results come from chlorophyll $b$-deficient soybean cultivars that only contain about half as much chlorophyll as their wild-type counterparts (Pettigrew et al. 1989). Even though the canopy extinction coefficients were similar between the mutant and wild-type plants, the chlorophyll-depleted cultivars outperformed the wild type by increasing the light penetration into the canopy.

Other changes to the plant architecture could also prove to be beneficial for maximizing the crop yield. For example, the wheat tiller inhibition (tin) mutant has a reduced number of tillers and fewer sterile tillers (Kebrom and Richards 2013). These plants use less water early in the growing season as compared to near-isogenic wild-type plants, which leaves them with more water available during the grain-filling period. When grown under water deficit, tin lines had larger and more grains per spikelet, offsetting the lower number of 
spikelets and producing a higher grain yield overall (Mitchell et al. 2013). It is conceivable that yield benefits might also be achieved under favorable conditions when the tin lines are grown at higher planting densities than current practice (Kebrom and Richards 2013; Mitchell et al. 2013).

\subsection{IMPROVING PHOTOSYNTHETIC PERFORMANCE BY QTL ANALYSIS WITH UTILIZING NATURAL GENETIC RESOURCES}

It is well recognized that there is wide intra- and interspecific variation in the rate of leaf photosynthesis. The utilization of these variations may be one of the important strategies for improving crop photosynthesis. Recent advances in molecular genetics have provided a lot of DNA markers, which facilitate identification of quantitative trait loci (QTL) for important agronomic traits (Yamamoto and Yano 2008). QTL analysis should be a useful approach to understand the genetic basis of the natural variation of leaf photosynthesis and will contribute to designing future breeding programs (Flood et al. 2011).

Most agronomic traits, such as plant height, seed number, and, of course, photosynthetic traits, are expressed in continuous values rather than a few discrete classes. These traits are called quantitative traits and are often controlled by multiple genetic factors. QTL analysis provides information about the number and location of QTLs on the genomes and the phenotypic effect of each QTL (Tanksley 1993; Figure 41.7). It is also possible to identify genes that underlie QTLs by high-resolution mapping, namely, map-based cloning (Yano 2001). It is expected that QTL analysis can find genes that are difficult to identify by mutant analysis (Ashikari and Matsuoka 2006). QTL analysis needs a segregating population consisting of different individuals. $\mathrm{F}_{2}$ and $\mathrm{BC}_{1} \mathrm{~F}_{1}$ populations are most frequently used in genetic analysis because of the relatively short time needed for their development, while populations such as recombinant inbred lines (RILs), backcrossed inbred lines (BILs), and chromosome segment substitution lines (CSSLs) are used in studies that aim to identify QTLs for complex traits (Yamamoto et al. 2014). Currently, genome-wide association studies (GWAS), which do not rely on a controlled bi-parental segregating population, are conducted to identify QTLs with the availability of large numbers of genetic markers such as single-nucleotide polymorphisms (SNPs) (Myles et al. 2009).

There are two options to identify QTLs associated with leaf photosynthesis. The first is direct measurements of leaf $\mathrm{CO}_{2}$ assimilation rate of a segregating population. An initial report of QTLs for $\mathrm{CO}_{2}$ assimilation rate is shown by Herve et al. (2001), who used sunflower RILs for genetic analysis. Subsequently, Teng et al. (2004) found two QTLs for $\mathrm{CO}_{2}$

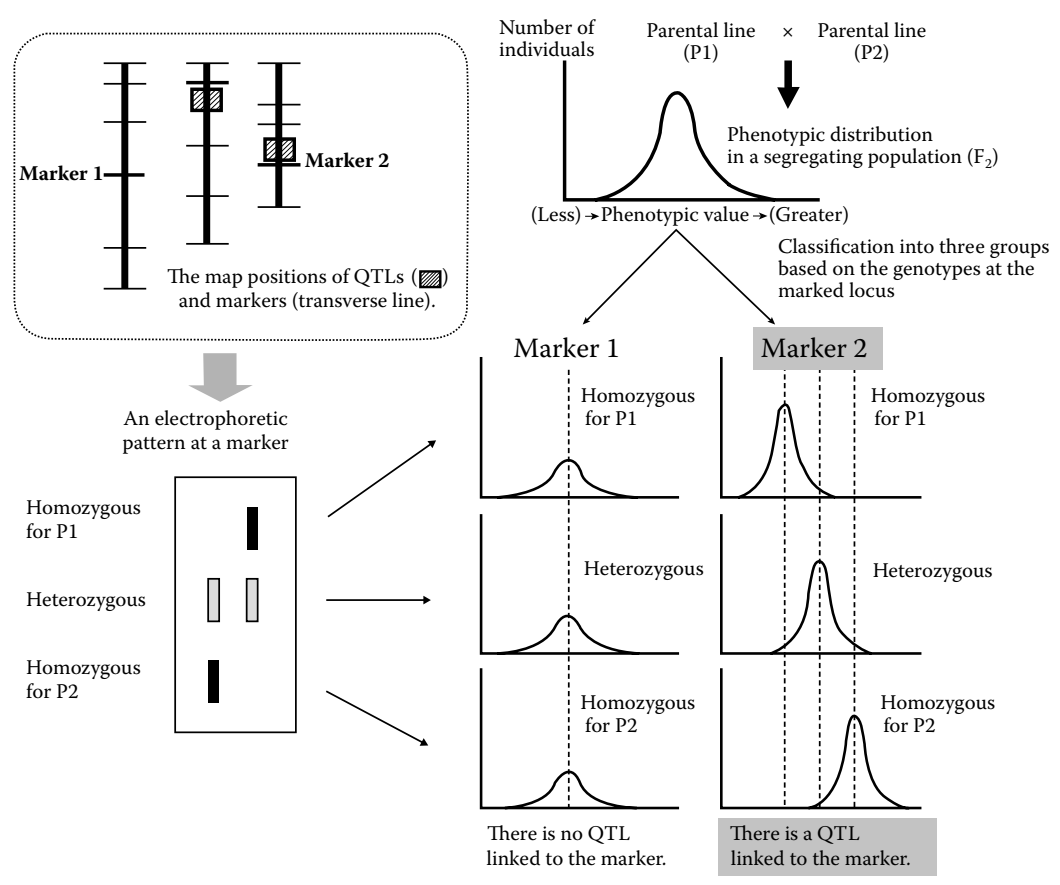

FIGURE 41.7 Mapping of quantitative trait loci. The phenotypic values for a particular trait of interest are evaluated using a segregating population such as $\mathrm{F}_{2}$. Subsequently, genotypes of DNA markers that are evenly spaced in the genome are analyzed. When no QTL locates near the marker, the average of the phenotypic value will be similar among the three groups that are classified based on the genotypes at the marker locus (Marker 1). When a QTL locates near the marker, the average of the phenotypic value will be significantly different among the groups (Marker 2). QTL analysis applies this analysis to all the DNA markers that are used and evaluates the number and location of QTLs and the phenotypic effect of each QTL. (Modified from Yamamoto T, Yano M, Kagaku 77, 607-613, 2007.) 
assimilation rate using double haploid (DH) lines derived from a cross between japonica and indica rice cultivars. $\mathrm{Hu}$ et al. (2009) and Gu et al. (2012) found several QTLs for rice photosynthesis using RILs and BILs lines, respectively, under both water-limited and well-watered conditions. Another option to identify QTLs is to evaluate phenotypic values of traits that are related to $\mathrm{CO}_{2}$ assimilation rate. Among those, the SPAD value is the simplest nondestructive index for chlorophyll content (Takai et al. 2013a). Chlorophyll fluorescence is also used to identify QTLs for several photosynthesisrelated traits (Yang et al. 2007; Guo et al. 2008; Liang et al. 2010; Czyczyło-Mysza et al. 2011; Kasajima et al. 2011). Furthermore, Rubisco and nitrogen content as well as carbon isotope discrimination $\left(\Delta^{13} \mathrm{C}\right)$, which reflects the ratio of leaf internal to external $\mathrm{CO}_{2}$ concentration $\left(C_{\mathrm{i}} / C_{\mathrm{a}}\right)$, have also been used for QTL analysis (Ishimaru et al. 2001; Laza et al. 2006; Takai et al. 2009; Khaembah et al. 2013).

The identification of the causal genes underlying QTLs for leaf photosynthesis is a major goal in these studies. Takai et al. (2013b) conducted high-resolution mapping for $\mathrm{CO}_{2}$ assimilation and identified the Green for Photosynthesis (GPS) gene that corresponds to the difference between an indica and a japonica rice cultivar. The analysis showed that the indicatype GPS gene increases $\mathrm{CO}_{2}$ assimilation rate by increasing Rubisco content, which might be attributed to enhancement of mesophyll numbers and leaf thickness. The sequencing analysis revealed that GPS encodes a plant-specific protein that may be involved in polar auxin transport (Qi et al. 2008) and is totally different from genes encoding components of plant photosynthetic apparatus.

DNA marker-assisted selection enables us to combine multiple QTLs, namely, QTL pyramiding. Adachi et al. (2014) combined two genetic regions from an indica rice in the genetic background of a japonica rice. The research showed that the pyramided line had significantly increased $\mathrm{CO}_{2}$ assimilation rates compared with japonica rice (Figure 41.8). Furthermore, it has been suggested that pyramiding of several QTLs has the potential to increase $\mathrm{CO}_{2}$ assimilation rate to even higher levels than those of parental lines (Adachi et al. 2013). Therefore, QTL pyramiding could be a promising approach for improving crop photosynthesis.

QTL analysis for leaf photosynthesis has become popular, although the number of studies for photosynthesis remains much lower than those for other important agronomic traits such as seed number, flowering time, and disease resistance (Yamamoto et al. 2009). Two things should be considered to facilitate QTL identification for leaf photosynthesis. The first is to enhance the measurement efficiency of gas exchange and related traits as these measurements are still labor-intensive and time-consuming (Adachi et al. 2011). The second is to decrease measurement variability because photosynthesis parameters are often influenced by environmental conditions and plant-to-plant variation that prevent the accurate evaluation of QTLs (Tanksley 1993).

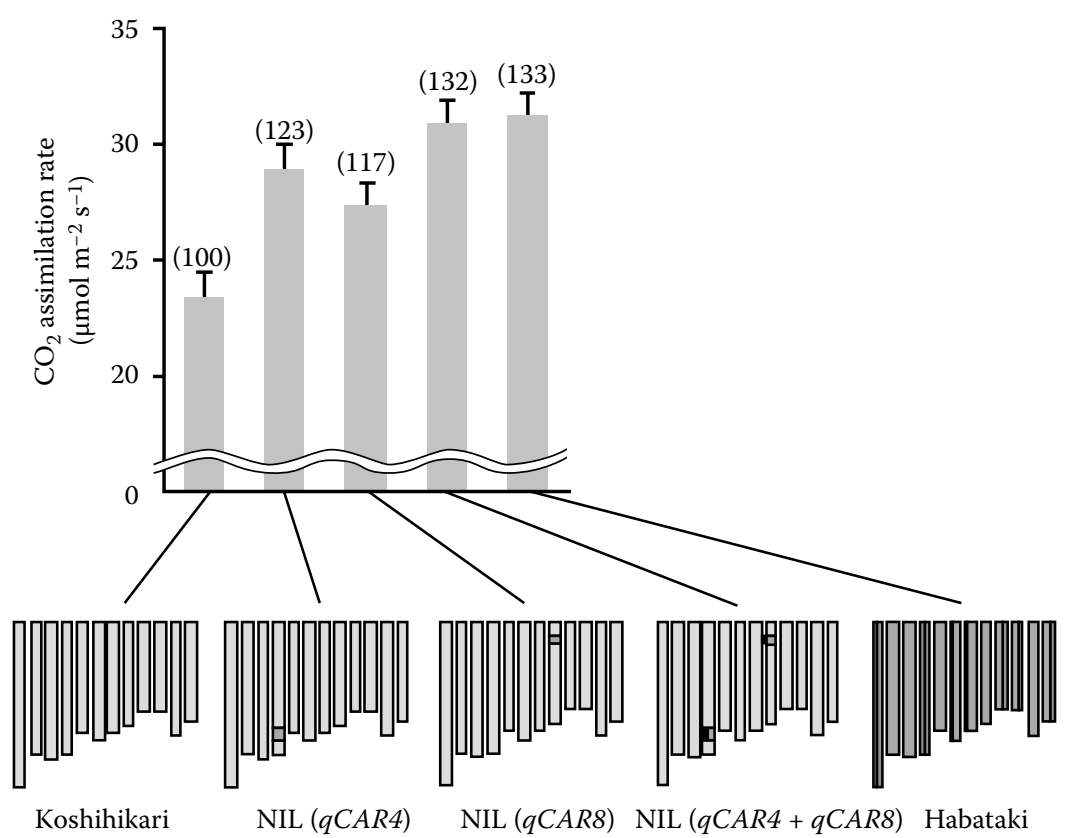

FIGURE 41.8 QTL pyramiding for $\mathrm{CO}_{2}$ assimilation rate. Koshihikari is a commercial japonica cultivar. Habataki is a high-yielding

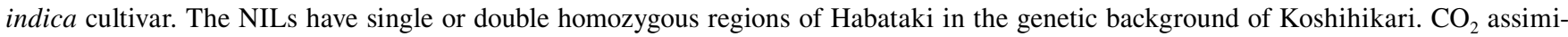
lation rates of flag leaves were measured at a photosynthetic photon flux density of $2000 \mu \mathrm{mol} \mathrm{m}^{-1} \mathrm{~s}^{-1}$, an ambient $\mathrm{CO}_{2}$ concentration of $370 \mu \mathrm{mol} \mathrm{mol}{ }^{-1}$, and an air temperature of $30^{\circ} \mathrm{C}$. Values in parentheses are percentages relative to Koshihikari. (Modified from Adachi S et al., Journal of Experimental Botany 65: 2049-2056, 2014.) 
The development of high-throughput measurement systems with high accuracy is a key factor for comprehensive understanding of the genetic basis of natural variation in photosynthesis.

\subsection{CONCLUSION}

The present rate of increase in crop yields is insufficient to keep pace with the rapid growth rates of the global population. Development of crops with increased yield and stress tolerance is essential to meet the future food and energy demands. Therefore, novel paths need to be explored to generate more efficient plants with higher production for the future. Enhancement of leaf photosynthetic capacity would provide one attractive avenue to drive increases in crop yields, since plant growth depends largely on its photosynthesis (Yamori 2013).

One could argue that plant photosynthesis cannot be improved, since its evolution has already perfected it. However, natural selection, which maximizes total fitness of the individual rather than agronomic yield, has shaped plant photosynthesis for life in environments that differ considerably from the resource-rich settings with little competition from other plants provided by modern agriculture (Leister 2012). The mutational constraints and selection pressures faced by higher plants, along with elements of historical contingency, have left us with a photosynthetic pathway that is far from perfect, but instead has been optimized to deal with the prevailing high $\mathrm{O}_{2}$ and low $\mathrm{CO}_{2}$ environment. The controlled conditions of the modern food production system force us to think about maximizing yield from the perspective of the entire crop canopy rather than of a single plant. The extent of our understanding of photosynthetic processes clearly indicates that enough scope has been left for improvements of this ancient and critical biological pathway to achieve our goals of sustainable food production.

\section{ACKNOWLEDGMENTS}

W.Y. was supported by the Japan Science and Technology Agency, PRESTO, by a Grant for Basic Science Research Projects from The Sumitomo Foundation, and in part by a Grant-in-Aid for Scientific Research from the Japan Society for the Promotion of Science (Scientific Research No. 25891005). F.B. was supported by the ARC Centre of Excellence for Translational Photosynthesis. S.A. was supported by the Japan Science and Technology Agency, PRESTO, and in part by a Grant-in-Aid for Scientific Research from the Japan Society for the Promotion of Science (Postdoctoral Fellowships).

\section{REFERENCES}

Adachi S, Nito N, Kondo M, Yamamoto T, Arai-Sanoh Y, Ando T, Ookawa T, Yano M, Hirasawa T (2011) Identification and characterization of genomic regions on chromosomes 4 and 8 that control the rate of photosynthesis in rice leaves. Journal of Experimental Botany 62: 1927-1938.
Adachi S, Nakae T, Uchida M, Soda K, Takai T, Oi T, Yamamoto $\mathrm{T}$ et al. (2013) The mesophyll anatomy enhancing $\mathrm{CO}_{2}$ diffusion is a key trait for improving rice photosynthesis. Journal of Experimental Botany 64: 1061-1072.

Adachi S, Baptista LZ, Sueyoshi T, Murata K, Yamamoto T, Ebitani T, Ookawa T, Hirasawa T (2014) Introgression of two chromosome regions for leaf photosynthesis from an indica rice into the genetic background of a japonica rice. Journal of Experimental Botany 65: 2049-2056.

André $\mathrm{M}$ (2011) Modelling ${ }^{18} \mathrm{O}_{2}$ and ${ }^{16} \mathrm{O}_{2}$ unidirectional fluxes in plants: II. Analysis of Rubisco evolution. Biosystems 103: 252-264.

Anten NPR, Schieving F, Werger MJA (1995) Patterns of light and nitrogen distribution in relation to whole canopy carbon gain in $\mathrm{C}_{3}$ and $\mathrm{C}_{4}$ mono- and dicotyledonous species. Oecologia 101: 504-513.

Araya T, Noguchi K, Terashima I (2006) Effects of carbohydrate accumulation on photosynthesis differ between sink and source leaves of Phaseolus vulgaris L. Plant and Cell Physiology 47: 644-652.

Ashikari M, Matsuoka M (2006) Identification, isolation and pyramiding of quantitative trait loci for rice breeding. Trends in Plant Science 11: 344-350.

Ashraf M, Akram NA (2009) Improving salinity tolerance of plants through conventional breeding and genetic engineering: An analytical comparison. Biotechnology Advances 27: 744-752.

Bauwe H, Hagemann M, Fernie AR (2010) Photorespiration: Players, partners and origin. Trends in Plant Science 15: 330-336.

Biswal AK, Pattanayak GK, Pandey SS, Leelavathi S, Reddy VS, Govindjee, Tripathy BC (2012) Light intensity-dependent modulation of chlorophyll $\mathrm{b}$ biosynthesis and photosynthesis by overexpression of chlorophyllide $a$ oxygenase in tobacco. Plant Physiology 159: 433-449.

Björkman O (1966) The effect of oxygen concentration on photosynthesis in higher plants. Physiologia Plantarum 19: 618-633.

Björkman O, Heisey WM, Nobs M, Nicholson F, Hart RW (1968) Effect of oxygen concentration on dry matter production in higher plants. Carnegie Institute Year Book. Carnegie Institute of Washington, Washington, DC, pp. 228-245.

Borland AM, Hartwell J, Weston DJ, Schlauch KA, Tschaplinski TJ, Tuskan GA, Yang X, Cushman JC (2014) Engineering crassulacean acid metabolism to improve water-use efficiency. Trends in Plant Science 19: 327-338.

Burkey KO (1994) Genetic variation of photosynthetic electron transport in barley: Identification of plastocyanin as a potential limiting factor. Plant Science 98: 177-187.

Burkey KO, Gizlice Z, Carter TE (1996) Genetic variation in soybean photosynthetic electron transport capacity is related to plastocyanin concentration in the chloroplast. Photosynthesis Research 49: 141-149.

Busch FA, Sage TL, Cousins AB, Sage RF (2013) $C_{3}$ plants enhance rates of photosynthesis by reassimilating photorespired and respired $\mathrm{CO}_{2}$. Plant, Cell \& Environment 36: 200-212.

Carvalho DD, Irving LJ, Carnevalli RA, Hodgson J, Matthew C (2006) Distribution of current photosynthate in two guinea grass (Panicum maximum Jacq.) cultivars. Journal of Experimental Botany 57: 2015-2024.

Chai MF, Chen QJ, An R, Chen YM, Chen J, Wang XC (2005) NADK2, an Arabidopsis chloroplastic NAD kinase, plays a vital role in both chlorophyll synthesis and chloroplast protection. Plant Molecular Biology 59: 553-564.

Chen M, Blankenship RE (2011) Expanding the solar spectrum used by photosynthesis. Trends in Plant Science 16: 427-431.

Chen M, Schliep M, Willows RD, Cai Z-L, Neilan BA, Scheer H (2010) A red-shifted chlorophyll. Science 329: 1318-1319. 
Cheng SH, Moore BD, Seemann JR (1998) Effects of short and long-term elevated $\mathrm{CO}_{2}$ on the expression of ribulose-1,5bisphosphate carboxylase/oxygenase genes and carbohydrate accumulation in leaves and Arabidopsis thaliana (L.) Heynh. Plant Physiology 116: 715-723.

Chida H, Nakazawa A, Akazaki H, Hirano T, Suruga K, Ogawa M, Satoh T et al. (2007) Expression of the algal cytochrome c6 gene in Arabidopsis enhances photosynthesis and growth. Plant \& Cell Physiology 48: 948-957.

Covshoff S, Hibberd JM (2012) Integrating $\mathrm{C}_{4}$ photosynthesis into $\mathrm{C}_{3}$ crops to increase yield potential. Current Opinion in Biotechnology 23: 209-214.

Crafts-Brandner SJ, Salvucci ME (2000) Rubisco activase constrains the photosynthetic potential of leaves at high temperature and $\mathrm{CO}_{2}$. Proceedings of the National Academy of Sciences of the United States of America 97: 13430-13435.

Czyczyło-Mysza I, Marcińska I, Skrzypek E, Chrupek M, Grzesiak S, Hura T, Stojałowski S, Myśków B, Milczarski P, Quarrie S (2011) Mapping QTLs for yield components and chlorophyll a fluorescence parameters in wheat under three levels of water availability. Plant Genetic Resources 9: 291-295.

DePaoli HC, Borland AM, Tuskan GA, Cushman JC, Yang X (2014) Synthetic biology as it relates to CAM photosynthesis: Challenges and opportunities. Journal of Experimental Botany 65: 3381-3393.

Dodd AN, Borland AM, Haslam RP, Griffiths H, Maxwell K (2002) Crassulacean acid metabolism: Plastic, fantastic. Journal of Experimental Botany 53: 569-580.

Evans JR (1989) Photosynthesis and nitrogen relationships in leaves of $\mathrm{C}_{3}$ plants. Oecologia 78(1): 9-19.

Evans JR, von Caemmerer S, Setchell BA, Hudson GS (1994) The relationship between $\mathrm{CO}_{2}$ transfer conductance and leaf anatomy in transgenic tobacco with a reduced content of Rubisco. Australian Journal of Plant Physiology 21: 475-495.

Evans JR, Kaldenhoff R, Genty B, Terashima I (2009) Resistances along the $\mathrm{CO}_{2}$ diffusion pathway inside leaves. Journal of Experimental Botany 60: 2235-2248.

Farquhar GD, von Caemmerer S, Berry JA (1980) A biochemical model of photosynthetic $\mathrm{CO}_{2}$ assimilation in leaves of $\mathrm{C}_{3}$ species. Planta 149: 78-90.

Feng L, Wang K, Li Y, Tan Y, Kong J, Li H, Zhu Y (2007) Overexpression of SBPase enhances photosynthesis against high temperature stress in transgenic rice plants. Plant Cell Report 26: 1635-1646.

Flexas J, Ribas-Carbó M, Hanson DT, Bota J, Otto B, Cifre J, McDowell N, Medrano H, Kaldenhoff R (2006) Tobacco aquaporin NtAQP1 is involved in mesophyll conductance to $\mathrm{CO}_{2}$ in vivo. The Plant Journal 48: 427-439.

Flood PJ, Harbinson J, Aarts MGM (2011) Natural genetic variation in plant photosynthesis. Trends in Plant Science 16: 327-335.

Galmés J, Kapralov MV, Andralojc PJ, Conesa MÀ, Keys AJ, Parry MAJ, Flexas J (2014a) Expanding knowledge of the Rubisco kinetics variability in plant species: Environmental and evolutionary trends. Plant, Cell and Environment 37: 1989-2001.

Galmés J, Andralojc PJ, Kapralov MV, Flexas J, Keys AJ, Molins A, Parry MAJ, Conesa MÀ (2014b) Environmentally driven evolution of Rubisco and improved photosynthesis and growth within the $\mathrm{C}_{3}$ genus Limonium (Plumbaginaceae). New Phytologist 203: 989-999.

Ghannoum O, Evans JR, Chow WS, Andrews TJ, Conroy JP, von Caemmerer S (2005) Faster Rubisco is the key to superior nitrogen use efficiency in NADP-Malic enzyme relative to NAD-Malic enzyme $\mathrm{C}_{4}$ grasses. Plant Physiology 137: $638-650$
Govindjee (2004) Chlorophyll a fluorescence: A bit of basics and history. In Chlorophyll a Fluorescence: A Signature of Photosynthesis, eds. Papageorgiou GC, Govindjee. Kluwer Academic Publishers, Dordrecht, pp. 1-42.

Grindlay DJC (1997) Towards and explanation of crop nitrogen demand based on the optimization of leaf nitrogen per unit area. Journal of Agricultural Science 128: 377-396.

Gu J, Yin X, Struik PC, Stomph TJ, Wang H (2012) Using chromosome introgression lines to map quantitative trait loci for photosynthesis parameters in rice (Oryza sativa L.) leaves under drought and well-watered field conditions. Journal of Experimental Botany 63: 455-469.

Guo PG, Baum M, Varshney RK, Graner A, Grando S, Ceccarelli S (2008) QTLs for chlorophyll and chlorophyll fluorescence parameters in barley under post-flowering drought. Euphytica 163: 203-214.

Haake V, Zrenner R, Sonnewald U, Stitt M (1998) A moderate decrease of plastid aldolase activity inhibits photosynthesis, alters the levels of sugars and starch, and inhibits growth of potato plants. The Plant Journal 14: 147-157.

Haake V, Geiger M, Walch-Liu P, Engels C, Zrenner R, Stitt M (1999) Changes in aldolase activity in wild-type potato plants are important for acclimation to growth irradiance and carbon dioxide concentration, because plastid aldolase exerts control over the ambient rate of photosynthesis across a range of growth conditions. The Plant Journal 17: 479-489.

Hajirezaei M-R, Peisker M, Tschiersch H, Palatnik JF, Valle EM, Carrillo N, Sonnewald U (2002) Small changes in the activity of chloroplastic $\mathrm{NADP}^{+}$-dependent ferredoxin oxidoreductase lead to impaired plant growth and restrict photosynthetic activity of transgenic tobacco plants. The Plant Journal 29: 281-293.

Hanba YT, Shibasaka M, Hayashi Y, Hayakawa T, Kasamo K, Terashima I, Katsuhara M (2004) Overexpression of the barley aquaporin HvPIP2; 1 increases internal $\mathrm{CO}_{2}$ conductance and $\mathrm{CO}_{2}$ assimilation in the leaves of transgenic rice plants. Plant \& Cell Physiology 45: 521-529.

Harrison EP, Willingham NM, Lloyd JC, Raines CA (1998) Reduced sedohepmlose-1,7-bisphosphatase levels in transgenic tobacco lead to decreased photosynthetic capacity and altered carbohydrate accumulation. Planta 204: 27-36.

Hatano-Iwasaki A, Ogawa K (2012) Biomass production is promoted by increasing an aldolase undergoing glutathionylation in Arabidopsis thaliana. The International Journal of Developmental Biology 6: 1-8.

Heckwolf M, Pater D, Hanson DT, Kaldenhoff R (2011) The Arabidopsis thaliana aquaporin AtPIP1;2 is a physiologically relevant $\mathrm{CO}_{2}$ transport facilitator. The Plant Journal 67: 795-804.

Henkes S, Sonnewald U, Badur R, Flachmann R, Stitt M (2001) A small decrease of plastid transketolase activity in antisense tobacco transformants has dramatic effects on photosynthesis and phenylpropanoid metabolism. The Plant Cell 13: 535-551.

Herve D, Fabre F, Berrios EF, Leroux N, Al Chaarani G, Planchon C, Sarrafi A, Gentzbittel L (2001) QTL analysis of photosynthesis and water status traits in sunflower (Helianthus annuus L.) under greenhouse conditions. Journal of Experimental Botany 52: 1857-1864.

Hikosaka K (1996) Effects of leaf age, nitrogen nutrition and photon flux density on the organization of the photosynthetic apparatus in leaves of a vine (Ipomoea tricolor Cav) grown horizontally to avoid mutual shading of leaves. Planta 198: 144-150.

Hikosaka K, Terashima I (1995) A model of the acclimation of photosynthesis in the leaves of $\mathrm{C}_{3}$ plants to sun and shade with respect to nitrogen use. Plant, Cell and Environment 18: 605-618. 
Hirose T, Werger MJA (1987) Maximizing daily canopy photosynthesis with respect to the leaf nitrogen allocation pattern in the canopy. Oecologia 72: 520-526.

Hölttä T, Vesala T, Sevanto S, Perämäki M, Nikinmaa E (2006) Modeling xylem and phloem water flows in trees according to cohesion theory and Münch hypothesis. Trees-Structure and Function 20: 67-78.

Hölttä T, Mencuccini M, Nikinmaa E (2009) Linking phloem function to structure: Analysis with a coupled xylem-Phloem transport model. Journal of Theoretical Biology 259: 325-337.

Hu SP, Zhou Y, Zhang L, Zhu XD, Li L, Luo LJ, Liu GL, Zhou QM (2009) Correlation and quantitative trait loci analyses of total chlorophyll content and photosynthetic rate of rice (Oryza sativa) under water stress and well-watered conditions. Journal of Integrative Plant Biology 51: 879-888.

Irving LJ, Robinson D (2006) A dynamic model of Rubisco turnover in cereal leaves. New Phvtologist 169: 493-504.

Ishimaru K, Kobayashi N, Ono K, Yano M, Ohsugi R (2001) Are contents of Rubisco, soluble protein and nitrogen in flag leaves of rice controlled by the same genetics? Journal of Experimental Botany 52: 1827-1833.

Izumi M, Wada S, Makino A, Ishida H (2010) The autophagic degradation of chloroplasts via Rubisco-containing bodies is specifically linked to leaf carbon status, but not nitrogen status in Arabidopsis. Plant Physiology 154: 1196-1209.

Kaldenhoff R (2012) Mechanisms underlying $\mathrm{CO}_{2}$ diffusion in leaves. Current Opinion in Plant Biology 15: 276-281.

Kasajima I, Ebana K, Yamamoto T, Takahara K, Yano M, KawaiYamada M, Uchimiya H (2011) Molecular distinction in genetic regulation of nonphotochemical quenching in rice. Proceedings of the National Academy of Sciences of the United States of America 138: 13835-13840.

Kawai S, Murata K (2008) Structure and function of NAD kinase and NADP phosphatase: Key enzymes that regulate the intracellular balance of $\mathrm{NAD}(\mathrm{H})$ and $\mathrm{NADP}(\mathrm{H})$. Bioscience, Biotechnology, and Biochemistry 72: 919-930.

Kebeish R, Niessen M, Thiruveedhi K, Bari R, Hirsch HJ, Rosenkranz R, Stäbler N, Schönfeld B, Kreuzaler F, Peterhänsel C (2007) Chloroplastic photorespiratory bypass increases photosynthesis and biomass production in Arabidopsis thaliana. Nature Biotechnology 25: 593-599.

Kebrom TH, Richards RA (2013) Physiological perspectives of reduced tillering and stunting in the tiller inhibition (tin) mutant of wheat. Functional Plant Biology 40: 977-985.

Khaembah EN, Irving LJ, Thom, ER, Faville MJ, Easton HS, Matthew C (2013) Leaf Rubisco turnover in a perennial ryegrass (Lolium perenne L.) mapping population: Genetic variation, identification of associated QTL, and correlation with plant morphology and yield. Journal of Experimental Botany 64: $1305-1316$.

Khush GS (2001) Green revolution: The way forward. Nature Reviews Genetics 2: 815-822.

Kossmann J, Sonnewald U, Willmitzer L (1994) Reduction of the chloroplastic fructose-1,6-bisphosphatase in transgenic potato plants impairs photosynthesis and plant growth. The Plant Journal 6: 637-650.

Kumar A, Li C, Portis Jr AR (2009) Arabidopsis thaliana expressing a thermostable chimeric Rubisco activase exhibits enhanced growth and higher rates of photosynthesis at moderately high temperatures. Photosvnthesis Research 100: 143-153.

Kurek I, Chang TK, Bertain SM, Madrigal A, Liu L, Lassner MW, Zhu G (2007) Enhanced thermostability of Arabidopsis Rubisco activase improves photosynthesis and growth rates under moderate heat stress. Plant Cell 19: 3230-3241.
Kusumi K, Hirotsuka S, Kumamaru T, Iba K (2012) Increased leaf photosynthesis caused by elevated stomatal conductance in a rice mutant deficient in SLAC1, a guard cell anion channel protein. Journal of Experimental Botany 63: 5635-5644.

Lambert RJ, Johnson RR (1978) Leaf angle, tassel morphology, and the performance of maize hybrids. Crop Science 18: 499-502.

Lattanzi FA, Schnyder H, Thornton B (2005) The sources of carbon and nitrogen supplying leaf growth. Assessment of the role of stores with compartmental models. Plant Physiology 137: 383-395.

Laza MR, Kondo M, Ideta O, Barlaan E, Imbe T (2006) Identification of quantitative trait loci for $\delta^{13} \mathrm{C}$ and productivity in irrigated lowland rice. Crop Science 46: 763-773.

Leakey AD, Ainsworth EA, Bernacchi CJ, Rogers A, Long SP, Ort DR (2009) Elevated $\mathrm{CO}_{2}$ effects on plant carbon, nitrogen, and water relations: Six important lessons from FACE. Journal of Experimental Botany 60: 2859-2876.

Lefebvre S, Lawson T, Zakhleniuk OV, Lloyd JC, Raines CA, Fryer M (2005) Increased sedoheptulose-1,7-bisphosphatase activity in transgenic tobacco plants stimulates photosynthesis and growth from an early stage in development. Plant Physiology 138: 451-460.

Leister D (2012) How can the light reactions of photosynthesis be improved in plants? Frontiers in Plant Science 3: 199.

Li P, Wang Y, Qian Q, Fu Z, Wang M, Zeng D, Li B, Wang X, Li J (2007) LAZY1 controls rice shoot gravitropism through regulating polar auxin transport. Cell Research 17: 402-410.

Liang Y, Zhang KP, Zhao L, Liu B, Meng QW, Tian JC, Zhao SJ (2010) Identification of chromosome regions conferring dry matter accumulation and photosynthesis in wheat (Triticum aestivum L.). Euphytica 171: 145-156.

Lichtentahler HK (1999) The 1-deoxy-d-xylulose-5-phosphate pathway of isoprenoid biosynthesis in plants. Annual Review of Plant Physiology and Plant Molecular Biology 50: 47-65.

Lin MT, Occhialini A, Andralojc PJ, Parry MAJ, Hanson MR (2014) A faster Rubisco with potential to increase photosynthesis in crops. Nature 513: 547-550.

Long SP, Zhu X-G, Naidu SL, Ort DR (2006) Can improvement in photosynthesis increase crop yields? Plant, Cell \& Environment 29: 315-330.

Mae T (1986) Partitioning and utilization of nitrogen in rice plants. Japan Agricultural Research Quarterly 20: 115-120.

Mae T, Ohira K (1981) The relationship of nitrogen related to leaf growth and senescence in rice plants (Oryza sativa L.). Plant and Cell Physiology 22: 1067-1074.

Mae T, Makino A, Ohira A (1983) Changes in the amounts of ribulose bisphosphate carboxylase synthesized and degraded during the life-span of rice life (Oryza sativa L.). Plant Physiology 24: 1079-1086.

Maier A, Fahnenstich H, von Caemmerer S, Engqvist MKM, Weber APM, Fluegge U-I, Maurino VG (2012) Transgenic introduction of a glycolate oxidative cycle into $A$. thaliana chloroplasts leads to growth improvement. Frontiers in Plant Science 3: 38.

Makino A (2003) Rubisco and nitrogen relationships in rice: Leaf photosynthesis and plant growth. Soil Science and Plant Nutrition 49: 319-327.

Makino A, Mae T, Ohira K (1983) Photosynthesis and ribulose 1,5-bisphosphate carboxylase in rice leaves. Plant Physiology 73: $1002-1007$.

Makino A, Mae T, Ohira K (1985) Photosynthesis and ribulose 1,5-bisphosphate carboxylase/oxygenase in rice leaves from emergence through senescence. Quantitative analysis by carboxylation/oxygenation and regeneration of ribulose 1,5-bisphosphate. Planta 166: 414-420. 
Makino A, Mae T, Ohira K (1988) Differences between wheat and rice in the enzymic properties of ribulose-1,5-bisphosphate carboxylase/oxygenase and the relationship to photosynthetic gas exchange. Planta 174: 30-38.

Makino A, Sakashita H, Hidema J, Mae T, Ojima K, Osmond B (1992) Distinctive responses of ribulose-1,5-bisphosphate carboxylase and carbonic anhydrase in wheat leaves to nitrogen nutrition and their possible relationships to $\mathrm{CO}_{2}$-transfer resistance. Plant Physiology 100: 1737-1743.

Makino A, Sato T, Nakano H, Mae T (1997) Leaf photosynthesis, plant growth and nitrogen allocation in rice under different irradiances. Planta 203: 390-398.

Makino A, Miyake C, Yokota A (2002) Physiological functions of the water-water cycle (Mehler reaction) and the cyclic electron flow around PSI in rice leaves. Plant and Cell Physiology 43: $1017-1026$.

Medrano H, Escalona JM, Bota J, Gulías J, Flexas J (2002) Regulation of photosynthesis of $\mathrm{C}_{3}$ plants in response to progressive drought: Stomatal conductance as a reference parameter. Annals of Botany 89: 895-905.

Melis A (2009) Solar energy conversion efficiencies in photosynthesis: Minimizing the chlorophyll antennae to maximize efficiency. Plant Science 177: 272-280.

Melis A, Neidhardt J, Benemann JR (1999) Dunaliella salina (Chlorophyta) with small chlorophyll antenna sizes exhibit higher photosynthetic productivities and photon use efficiencies than normally pigmented cells. Journal of Applied Phycology 10: 515-525.

Michelet L, Zaffagnini M, Morisse S, Sparla F, Perez-Perez ME, Francia F, Danon A et al. (2013) Redox regulation of the Calvin-Benson cycle: Something old, something new. Frontiers in Plant Science 4: 470.

Mitchell JH, Rebetzke GJ, Chapman SC, Fukai S (2013) Evaluation of reduced-tillering (tin) wheat lines in managed, terminal water deficit environments. Journal of Experimental Botany 64: 3439-3451.

Miyagawa Y, Tamoi M, Shigeoka S (2001) Overexpression of a cyanobacterial fructose-1,6-/sedoheptulose-1,7-bisphosphatase in tobacco enhances photosynthesis and growth. Nature Biotechnology 19: 965-969.

Miyashita H, Ikemoto H, Kurano N, Adachi K, Chihara M, Miyachi S (1996) Chlorophyll $d$ as a major pigment. Nature 383: 402.

Moore BD, Cheng SH, Rice J, Seemann JR (1998) Sucrose cycling, Rubisco expression, and prediction of photosynthetic acclimation to elevated atmospheric $\mathrm{CO}_{2}$. Plant, Cell and Environment 21: 905-915.

Moore BD, Cheng SH, Sims D, Seemann JR (1999) The biochemical and molecular basis for photosynthetic acclimation to elevated atmospheric $\mathrm{CO}_{2}$. Plant, Cell and Environment 22: 567-582.

Morris PF, Layzell DB, Canvin DT (1988) Ammonia production and assimilation in glutamate synthase mutants of Arabidopsis thaliana. Plant Physiology 87: 148-154.

Mueller-Cajar O, Stotz M, Wendler P, Hartl FU, Bracher A, Hayer-Hartl M (2011) Structure and function of the AAA+ protein CbbX, a red-type RuBisCO activase. Nature 479: 194-199.

Myles S, Peiffer J, Brown PJ, Ersoz ES, Zhang Z, Costich DE, Buckler ES (2009) Association mapping: Critical considerations shift from genotyping to experimental design. Plant Cell 21: 2194-2202.

Nikinmaa E, Hölttä T, Hari P, Kolari P, Mäkelä A, Sevanto A, Vesala T (2013) Assimilate transport in phloem sets conditions for leaf gas exchange. Plant, Cell and Environment 36: $655-669$.
Ölcer H, Lloyd JC and Raines CA (2001) Photosynthetic capacity is differentially affected by reductions in sedoheptulose1,7-bisphosphatase activity during leaf development in transgenic tobacco plants. Plant Physiology 125: 982-989.

Ort DR, Zhu X, Melis A (2011) Optimizing antenna size to maximize photosynthetic efficiency. Plant Physiology 155: $79-85$.

Parry MAJ, Keys AJ, Madgwick PJ, Carmo-Silva AE, Andralojc PJ (2008) Rubisco regulation: A role for inhibitors. Journal of Experimental Botany 59: 1569-1580.

Payne JL, Boyer AG, Brown JH, Finnegan S, Kowalewski M, Krause RA, Lyons SK, McClain CR, McShea DW, NovackGottshall PW, Smith FA, Stempien JA, Wang SC (2009) Twophase increase in the maximum size of life over 3.5 billion years reflects biological innovation and environmental opportunity. Proceedings of the National Academy of Sciences of the United States of America 106: 24-27.

Pego JV, Kortstee AJ, Huijser C, Smekens SCM (2000) Photosynthesis, sugars and the regulation of gene expression. Journal of Experimental Botany 51: 407-416.

Pesaresi P, Scharfenberg M, Weigel M, Granlund I, Schroder WP, Finazzi G, Rappaport F et al. (2009) Mutants, overexpressors, and interactors of Arabidopsis plastocyanin isoforms: Revised roles of plastocyanin in photosynthetic electron flow and thylakoid redox state. Molecular Plant 2: 236-248.

Petit JR, Jouzel J, Raynaud D, Barkov NI, Barnola JM, Basile I, Bender M et al. Saltzman E, Stievenard M (1999) Climate and atmospheric history of the past 420,000 years from the Vostok ice core, Antarctica. Nature 399: 429-436.

Pettigrew WT, Hesketh JD, Peters DB, Woolley JT (1989) Characterization of canopy photosynthesis of chlorophylldeficient soybean isolines. Crop Science 29: 1025-1029.

Portis Jr AR (2003) Rubisco activase: Rubisco's catalytic chaperone. Photosynthesis Research 75: 11-27.

Pribil M, Pesaresi P, Hertle A, Barbato R, Leister D (2010) Role of plastid protein phosphatase TAP38 in LHCII dephosphorylation and thylakoid electron flow. PLoS Biology 8: e1000288.

Price GD, Badger MR, von Caemmerer S (2011) The prospect of using cyanobacterial bicarbonate transporters to improve leaf photosynthesis in $\mathrm{C}_{3}$ crop plants. Plant Physiology 155: 20-26.

Price GD, Pengelly JJL, Forster B, Du J, Whitney SM, von Caemmerer S, Badger MR, Howitt SM, Evans JR (2013) The cyanobacterial CCM as a source of genes for improving photosynthetic $\mathrm{CO}_{2}$ fixation in crop species. Journal of Experimental Botany 64: 753-768.

Qi J, Qian Q, Bu Q, Li S, Chen Q, Sun J, Liang W et al. Chen J, Chen M, Li C (2008) Mutation of the rice Narrow leafl gene, which encodes a novel protein, affects vein patterning and polar auxin transport. Plant Physiology 147: 1947-1959.

Raines CA (2003) The Calvin cycle revisited. Photosynthesis Research 75: 1-10.

Raines CA (2011) Increasing photosynthetic carbon assimilation in $\mathrm{C}_{3}$ plants to improve crop yield: Current and future strategies. Plant Physiology 155: 36-42.

Raven JA (2000) Land plant biochemistry. Philosophical Transactions of the Royal Society of London B 355: 833-846.

Roberts L (2011) 9 billion? Science 333: 540-543.

Rodriguez RE, Lodeyro A, Poli HO, Zurbriggen M, Palatnik JF, Tognetti VB, Tschiersch $\mathrm{H}$ et al. Transgenic tobacco plants overexpressing chloroplastic ferredoxin-NADP $(\mathrm{H})$ reductase display normal rates of photosynthesis and increased tolerance to oxidative stress. Plant Physiology 143: 639-649. 
Rosenthal D, Locke A, Khozaei M, Raines C, Long S, Ort D (2011) Over-expressing the $\mathrm{C}_{3}$ photosynthesis cycle enzyme sedoheptulose-1-7 bisphosphatase improves photosynthetic carbon gain and yield under fully open air $\mathrm{CO}_{2}$ fumigation (FACE). BMC Plant Biology 11: 123.

Sage RF (2004) The evolution of $\mathrm{C}_{4}$ photosynthesis. New Phytologist 161: 341-370.

Sage RF, Sage TL, Kocacinar F (2012) Photorespiration and the evolution of $\mathrm{C}_{4}$ photosynthesis. Annual Review of Plant Biology 63: $19-47$.

Sakamoto T, Morinaka Y, Ohnishi T, Sunohara H, Fujioka S, UeguchiTanaka M, Mizutani M, Sakata K, Takatsuto S, Yoshida S, Tanaka H, Kitano H, Matsuoka M (2006) Erect leaves caused by brassinosteroid deficiency increase biomass production and grain yield in rice. Nature Biotechnology 24: 105-109.

Salvucci ME, Crafts-Brandner SJ (2004a) Relationship between the heat tolerance of photosynthesis and the thermal stability of Rubisco activase in plants from contrasting thermal environments. Plant Physiology 134: 1460-1470.

Salvucci ME, Crafts-Brandner SJ (2004b) Inhibition of photosynthesis by heat stress: The activation state of Rubisco as a limiting factor in photosynthesis. Physiologia Plantarum 120: 179-186.

Salvucci ME, DeRidder BP, Portis AR (2006) Effect of activase level and isoform on the thermotolerance of photosynthesis in Arabidopsis. Journal of Experimental Botany 57: 3793-3799.

Schopf JW (2014) Geological evidence of oxygenic photosynthesis and the biotic response to the 2400-2200 Ma "great oxidation event". Biochemistry 79: 165-177.

Schöttler MA, Kirchhoff H, Weis E (2004) The role of plastocyanin in the adjustment of the photosynthetic electron transport to the carbon metabolism in tobacco. Plant Physiology 136: 4265-4274.

Sevanto S (2014) Phloem transport and drought. Journal of Experimental Botany 65: 1751-1759.

Spreitzer RJ, Salvucci ME (2002) Rubisco: Interactions, associations and the possibilities of a better enzyme. Annual Review of Plant Biology 53: 449-475.

Stotz M, Mueller-Cajar O, Ciniawsky S, Wendler P, Hartl FU, Bracher A, Hayer-Hartl M (2011) Structure of green-type RuBisCO activase from tobacco. Nature Structural \& Molecular Biology 18: 1366-1370.

Studer RA, Christin PA, Williams MA, Orengo CA (2014) Stabilityactivity tradeoffs constrain the adaptive evolution of RubisCO. Proceedings of the National Academy of Sciences of the United States of America 111: 2223-2228.

Sudo E, Suzuki Y, Makino A (2014) Whole plant growth and N utilization in transgenic rice plants with increased or decreased Rubisco content under different $\mathrm{CO} 2$ partial pressures. Plant and Cell Physiology 55: 1905-1911.

Takahara K, Kasajima I, Takahashi H, Hashida SN, Itami T, Onodera H, Toki S, Yanagisawa S, Kawai-Yamada M, Uchimiya H (2010) Metabolome and photochemical analysis of rice plants overexpressing Arabidopsis NAD kinase gene. Plant Physiology 152: 1863-1873.

Takai T, Ohsumi A, San-Oh Y, Laza MRC, Kondo M, Yamamoto T, Yano M (2009) Detection of a quantitative trait locus controlling carbon isotope discrimination and its contribution to stomatal conductance in japonica rice. Theoretical and Applied Genetics 118: 1401-1410.

Takai T, Ohsumi A, Arai Y, Iwasawa N, Yano M, Yamamoto T, Yoshinaga S, Kondo M (2013a) QTL analysis of leaf photosynthesis in rice. Japan Agricultural Research Quarterly: JARQ 47: 227-235.
Takai T, Adachi S, Taguchi-Shiobara F, Sanoh-Arai Y, Iwasawa N, Yoshinaga S, Hirose S et al. (2013b) A natural variant of NAL1, selected in high-yield rice breeding programs, pleiotropically increases photosynthesis rate. Scientific Report 3: 2149.

Tamoi M, Nagaoka M, Miyagawa Y, Shigeoka S (2006) Contribution of fructose-1,6-bisphosphatase and sedoheptulose-1,7-bispho sphatase to the photosynthetic rate and carbon flow in the Calvin cycle in transgenic plants. Plant \& Cell Physiology 47: 380-390.

Tanaka Y, Sugano SS, Shimada T, Hara-Nishimura I (2013) Enhancement of leaf photosynthetic capacity through increased stomatal density in Arabidopsis. New Phytologist 198: 757-764.

Tanksley SD (1993) Mapping polygenes. Annual Review of Genetics 27: 205-233.

Teng S, Qian Q, Zeng D, Kunihiro Y, Fujimoto K, Huang D, Zhu L (2004) QTL analysis of leaf photosynthetic rate and related physiological traits in rice (Oryza sativa L.). Euphytica 135: $1-7$.

Terashima I, Hanba YT, Tholen D, Niinemets Ü (2011) Leaf functional anatomy in relation to photosynthesis. Plant Physiology 155: $108-116$.

Tholen D, Zhu XG (2011) The mechanistic basis of internal conductance: A theoretical analysis of mesophyll cell photosynthesis and $\mathrm{CO}_{2}$ diffusion. Plant Physiology 156: 90-105.

Uematsu K, Suzuki N, Iwamae T, Inui M, Yukawa H (2012) Increased fructose 1,6-bisphosphate aldolase in plastids enhances growth and photosynthesis of tobacco plants. Journal of Experimental Botany 63: 3001-3009.

Vassey TL, Quick WP, Sharkey TD, Stitt M (1991) Water stress, carbon dioxide, and light effects on sucrose-phosphate synthase activity in Phaseolus vulgaris. Physiologia Plantarum 81: 37-44.

von Caemmerer S, Quick WP, Furbank RT (2012) The development of $\mathrm{C}_{4}$ rice: Current progress and future challenges. Science 336: 1671-1672.

Whitney SM, Sharwood RE, Orr D, White SJ, Alonso H, Galmés J (2011) Isoleucine 309 acts as a $\mathrm{C}_{4}$ catalytic switch that increases ribulose-1,5-bisphosphate carboxylase/oxygenase (Rubisco) carboxylation rate in Flaveria. Proceedings of the National Academy of Sciences of the United States of America 108: 14688-14693.

Wigge B, Krömer S, Gardeström P (1993) The redox levels and subcellular distribution of pyridine nucleotides in illuminated barley leaf protoplasts studied by rapid fractionation. Physiologia Plantarum 88: 10-18.

Woodrow IE (2009) Flux control analysis of the rate of photosynthetic $\mathrm{CO}_{2}$ assimilation. In Photosynthesis in Silico, eds. Laiska A, Nedbal L, Govindjee. Springer, Dordrecht, pp. 349-360.

Wright IJ, Reich PB, Westoby M, Ackerly DD, Baruch Z, Bongers F, Cavender-Bares J (2004) The worldwide leaf economics spectrum. Nature 428: 821-827.

Yamamoto T, Yano M (2007) Application of the rice genome information to the molecular breeding. Kagaku 77: 607-613.

Yamamoto T, Yano M (2008) Detection and molecular cloning of genes underlying quantitative phenotypic variations in rice. In Rice Biology in the Genomics Era, eds. Hirano HY, Sano Y, Hirai A, Sasaki T. Springer, Berlin, Heidelberg, pp. 295-308.

Yamamoto H, Kato H, Shinzaki Y, Horiguchi S, Shikanai T, Hase T, Endo T et al. (2006) Ferredoxin limits cyclic electron flow around PSI (CEF-PSI) in higher plants: Stimulation of CEFPSI enhances non-photochemical quenching of Chl fluorescence in transplastomic tobacco. Plant \& Cell Physiology 47: 1355-1371. 
Yamamoto T, Yonemaru J, Yano M (2009) Towards the understanding of complex traits in rice: Substantially or superficially? DNA Research 16: 141-154.

Yamamoto T, Uga Y, Yano M (2014) Genomics-assisted allele mining and its integration into rice breeding. In Genomics of Plant Genetic Resources, Volume 2. Crop Productivity, Food Security and Nutritional Quality, eds. Tuberosa R, Graner A, Frison E. Springer, Dordrecht, pp. 251-265.

Yamori W (2013) Improving photosynthesis to increase food and fuel production by biotechnological strategies in crops. J Plant Biochem \& Physiol 1: 1-13.

Yamori W, Shikanai T, Makino A (2015) Photosystem I cyclic electron flow via chloroplast NADH dehydrogenase-like complex performs a physiological role for photosynthesis at low light. Scientific Reports 5: 13908.

Yamori W, von Caemmerer S (2009) Effect of Rubisco activase deficiency on the temperature response of $\mathrm{CO}_{2}$ assimilation rate and Rubisco activation state: Insights from transgenic tobacco with reduced amounts of Rubisco activase. Plant Physiology 151: 2073-2082.

Yamori W, Suzuki K, Noguchi K, Nakai M, Terashima I (2006) Effects of Rubisco kinetics and Rubisco activation state on the temperature dependence of the photosynthetic rate in spinach leaves from contrasting growth temperatures. Plant, Cell \& Environment 29: 1659-1670.

Yamori W, Noguchi K, Kashino Y, Terashima I (2008) The role of electron transport in determining the temperature dependence of the photosynthetic rate in spinach leaves grown at contrasting temperatures. Plant \& Cell Phvsiology 49: 583-591.
Yamori W, Takahashi S, Makino A, Price GD, Badger MR, von Caemmerer S (2011) The roles of ATP synthase and the cytochrome $\mathrm{b}_{6} / \mathrm{f}$ complexes in limiting chloroplast electron transport and determining photosynthetic capacity. Plant Physiology 155: 956-962.

Yamori W, Masumoto C, Fukayama H, Makino A (2012) Rubisco activase is a key regulator of non steady-state photosynthesis at any leaf temperature and, to a lesser extent, of steady-state photosynthesis at high temperature. The Plant Journal 71: 871-880.

Yamori W, Hikosaka K, Way DA (2014) Temperature response of photosynthesis in $\mathrm{C}_{3}, \mathrm{C}_{4}$ and CAM plants: Temperature acclimation and temperature adaptation. Photosynthesis Research 119: 101-117.

Yang DL, Jing RL, Chang XP, Li W (2007) Quantitative trait loci mapping for chlorophyll fluorescence and associated traits in wheat (Triticum aestivum). Journal of Integrative Plant Biology 49: 646-654.

Yano M (2001) Genetic and molecular dissection of naturally occurring variation. Current Opinion in Plant Biology 4: 130-135.

Yoshihara T, Spalding EP, Iino M (2013) AtLAZY1 is a signaling component required for gravitropism of the Arabidopsis thaliana inflorescence. The Plant Journal 74: 267-279.

Zhang J, Ku LX, Han ZP, Guo SL, Liu HJ, Zhang ZZ, Cao LR, Cui XJ, Chen YH (2014) The ZmCLA4 gene in the $q L A 4-1$ QTL controls leaf angle in maize (Zea mays L.). Journal of Experimental Botany 65: 5063-5076.

Zhu X-G, Long SP, Ort DR (2010) Improving photosynthetic efficiency for greater yield. Annual Review of Plant Biology 61: 235-261. 